\title{
What Can be Learnt on Biologically Relevant Systems From the Topological Analysis of the Electron Localization Function?
}

J.-P. PIQUEMAL ${ }^{1,2}$ J. PILMÉ, ${ }^{1,2,3}$ O. PARISEL ${ }^{1,2}$ H. GÉRARD, ${ }^{1,2}$ I. FOURRÉ, ${ }^{1,2}$ J. BERGÈS, ${ }^{1,2}$ C. GOURLAOUEN, ${ }^{1,2^{*}}$ A. DE LA LANDE, ${ }^{1,2 \uparrow}$ M.-C. VAN SEVEREN, ${ }^{1,2}$ B. SILVI ${ }^{1,2}$ ${ }^{1}$ UPMC Univ Paris 06, UMR 7616, Laboratoire de Chimie Théorique, Case Courrier 137, 4 Place Jussieu, F-75005 Paris, France

${ }^{2}$ CNRS, UMR 7616, Laboratoire de Chimie Théorique, Case Courrier 137, 4 Place Jussieu, F-75005, Paris, France

${ }^{3}$ Université de Lyon, Université Lyon 1, Faculté de pharmacie, F-69373 Lyon, Cedex 08, France

Received 3 March 2008; accepted 7 March 2008

Published online 30 April 2008 in Wiley InterScience (www.interscience.wiley.com).

DOI 10.1002/qua.21711

\begin{abstract}
The topological analysis of the electron localization function (ELF) provides a convenient mathematical framework enabling an unambiguous characterization of bonds and more particularly in terms of bond types. In this contribution, we present an overview of the applications of this approach to biological and biomimetic systems.

(ㅇ) 2008 Wiley Periodicals, Inc. Int J Quantum Chem 108: 1951-1969, 2008
\end{abstract}

Key words: hydrogen bond; electron localization function; topological analysis; population analysis; delocalization; charge transfer

Correspondence to: B. Silvi; e-mail: silvi@lct.jussieu.fr

* Present address: Institute of Chemical Research of Catalonia (ICIQ), Av. Països Catalans 16, E. 43007 Tarragona, Spain.

Present address: Institute of Biocomplexity and Informatics, Department of Chemistry, University of Calgary, 2500 University Drive NW, Calgary, Alberta, Canada T2N 1N4. 


\section{From Complexity to a Simple Description of Active Sites}

$\mathbf{U}$ nderstanding the chemistry of complex systems of biophysical interest often implies a severe reductionism by which the attention is focused on a few 10 atoms among thousands. This is not only the result of some existing difficulty in the modeling of such systems, but rather a consequence of the content of the chemical concepts and of the representation of the matter at the atomic scale in which chemical reactions are local events involving the breaking and the formation of bonds between atoms. This follows the general scheme outlined below.

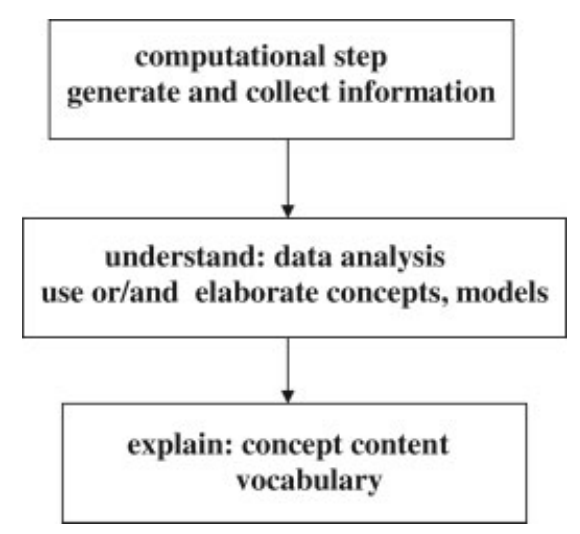

The link between the chemical language and the quantum mechanical computation which generates the data is not as straightforward as thought because the rough information provided by quantum mechanics consists in observables, subobservables and density of probability distributions of a system of interacting particles ruled by the Schrödinger equation. This is not the representation of Chemistry for which any system is an assembly of atoms linked by bonds whose properties are determined by the chemical composition, that is, stoichiometry or position of the elements in the periodic table.

Two main strategies have been proposed up to now. The traditional analysis carried out by quantum chemists consist in a projection of the wave function onto molecular orbitals (MO) or valencebond (VB) structures (the so-called Hilbert space partitioning). For a long time the MO and VB approaches have been artificially opposed although they participate of the same philosophy, that is, the interpretation of the wave function. In fact, rather than achieving a true partition of the Hilbert space, a physical meaning is given to the calculus used to obtain an approximate wave function. This has been criticized by C. A. Coulson who wrote: "This epistemological difficulty is mostly due to the weakness of interpretative methods that give a physical significance to quantities, such as molecular orbitals or valence bond structures, appearing as intermediates during the course of approximate procedures of solution of the many-body Schrödinger equation" [1].

Instead of interpretating the wave function, it is possible to consider a geometrical space description in order to deduce from observables and related quantities the "good old" chemical concepts of atoms, bond, and lone pairs. The concept of "electronic domain" introduced by Gillespie in the context of the VSEPR (Valence Shell Electron Pair Repulsion) model provides a link between the bond line description and a partition of the molecular space into nonoverlapping regions dominated by an opposite spin pair or by a single electron in the case of radicals. The VSEPR model points out that the geometry of a molecule appears to depend on the total number of electron pairs in the valence shell of the central atom. This model predicts the most probable arrangement of the electronic domains around an atomic center and then the equilibrium geometry of the nuclei. This model can be considered as a corollary of the Hohenberg and Kohn first theorem since it provides a correspondence between a property of the density (the arrangement of the domain) and the molecular geometry [the external potential in the Density Functional Theory (DFT) vocabulary]. The electronic domains can be defined mathematically as the basins of the gradient vector field of an ad hoc function for which the Becke \& Edgcombe's Electron Localization Function (ELF) provides an excellent estimate [2]. As mentioned by Gillespie and Robinson [3]: “This function exhibits maxima at the most probable positions of localized electron pairs and each maximum is surrounded by a basin in which there is an increased probability of finding an electron pair. These basins correspond to the qualitative electron pair domains of the VSEPR model and have the same geometry as the VSEPR domains."

The aim of this article is to review the applications of ELF in the fields of biochemistry and biophysics to precise the possibilities and limits of the method. 


\section{A Sketch of the ELF Analysis}

The aim of the method is to provide a mathematically sound framework enabling a partition of the three-dimensional coordinate space in adjacent regions fulfilling as well as possible a one to one correspondence with the chemical objects of Lewis's valence theory $[4,5]$. The gradient dynamical system theory [6, 7] appears to be a very reliable and appropriate tool that has already been successful in the context of Richard Bader's AIM theory [8]. Consider a local function, say $\eta(\mathbf{r})$ called potential function in the dynamical system theory context, which carries the chemical information; its gradient $\nabla \eta(\mathbf{r})$ forms a vector field bounded on $\mathbf{R}^{3}$. The $\nabla \eta(\mathbf{r})$ field determines two types of points: on the one hand the wandering points at which $\nabla \eta(\mathbf{r}) \neq 0$ and, on the other hand, the critical points which correspond to $\nabla \eta(\mathbf{r})=0$. The critical points are characterized by their index, which is the number of positive eigenvalues of the second derivative (Hessian) matrix of $\eta(\mathbf{r})$. The formal analogy with a velocity field (i.e., $\nabla \eta(\mathbf{r})=d \mathbf{r} / d t$ ) enables to build trajectories by integrating over the time variable. Each trajectory starts in the neighborhood of a point (or set of points) called the $\alpha$-limit for which $\nabla \eta(\mathbf{r})=0$ and ends in the neighborhood of another point (or set of points) called the $\omega$-limit for which $\nabla \eta(\mathbf{r})=0$. Except for asymptotic behaviors, the $\alpha$ - and $\omega$-limits are critical points. The set of trajectories having a given critical point as $\omega$-limit is called the stable manifold of this critical point; its unstable manifold is the set of trajectories for which it is a $\alpha$-limit. The stable manifold of a critical point of index 0 (a local maximum or attractor) is the basin of the attractor; that of a critical point of index larger than 0 is a separatrix: it is the boundary between basins.

As already mentioned, it is the "potential" function $\eta(\mathbf{r})$ that provides the chemical information. ELF $[2,9-11]$ is derived from the measure of the Fermi hole curvature and interpreted in terms of local excess kinetic energy because of Pauli repulsion. It is confined to the $[1,0]$ interval to tend to 1 where parallel spins are highly improbable (there us therefore a high probability of opposite-spin pairs), and to zero in regions where there is a high probability of same-spin pairs. Another local descriptor of the pair formation in the sense of Lewis's model, the so-called spin pair composition, has recently been introduced on the basis of the twoparticle probability density analysis [11]. This function is defined as the ratio of same-spin and opposite-spin pair functions integrated over a sampling volume around the reference point:

$$
\mathcal{C}_{\pi}(\mathbf{r})=\bar{N}(\mathbf{r})^{-2 / 3} \bar{N}_{\bar{N}_{\perp}(\mathbf{r})}
$$

with:

$$
\begin{gathered}
\bar{N}(\mathbf{r})=\int_{V} \rho\left(\mathbf{r}_{1}\right) d \mathbf{r}_{1} \\
\bar{N}_{\|}(\mathbf{r})=\iint_{V V} \pi^{\alpha \alpha}\left(\mathbf{r}_{1}, \mathbf{r}_{2}\right) d \mathbf{r}_{1} d \mathbf{r}_{2}+\iint_{V V} \pi^{\beta \beta}\left(\mathbf{r}_{1}, \mathbf{r}_{2}\right) d \mathbf{r}_{1} d \mathbf{r}_{2} \\
\bar{N}_{\perp}(\mathbf{r})=\iint_{V V} \pi^{\alpha \beta}\left(\mathbf{r}_{1}, \mathbf{r}_{2}\right) d \mathbf{r}_{1} d \mathbf{r}_{2}+\iint_{V V} \pi^{\beta \alpha}\left(\mathbf{r}_{1}, \mathbf{r}_{2}\right) d \mathbf{r}_{1} d \mathbf{r}_{2}
\end{gathered}
$$

In these equations, $\rho(\mathbf{r})$ is the spinless one electron density distribution function, and $\pi^{\sigma \sigma^{\prime}}\left(\mathbf{r}_{1}, \mathbf{r}_{2}\right)$ the $\sigma \sigma^{\prime}$ component of the two-particle distribution $\pi\left(\mathbf{r}_{1}, \mathbf{r}_{2}\right)$. It has been shown that ELF is an excellent approximation to this function once put in the Lorentzian form. ELF has the advantage that it can be expressed analytically in terms of basis functions in all practical cases where the wave function is expressed in terms of orbitals, whereas the spin pair composition must be calculated numerically.

The topological partition of the ELF gradient field $[12,13]$ yield basins of attractors, which can be thought as corresponding to bonds and lone pairs. In a molecule, one can find two types of basins. On the one hand, core basins surrounding nuclei with atomic number $\mathrm{Z}>2$ and labeled $\mathrm{C}(\mathrm{A})$ where $\mathrm{A}$ is the atomic symbol of the element and, on the other hand, are valence basins. The valence basins are characterized by the number of atomic valence shells to which they participate, or, in other words, by the number of core basins with which they share a boundary. This number is called the synaptic order. Thus, there are monosynaptic, disynaptic, trisynaptic basins, and so on. Monosynaptic basins, labeled $\mathrm{V}(\mathrm{A})$, correspond to the lone pairs of the Lewis model and polysynaptic basins to the shared pairs of the Lewis model. In particular, disynaptic basins, labeled $\mathrm{V}(\mathrm{A}, \mathrm{X})$, correspond to two-center bonds, trisynaptic basins, labeled $\mathrm{V}(\mathrm{A}, \mathrm{X}, \mathrm{Y})$, to 
three-center bonds and so on. The valence shell of a molecule is the union of its valence basins. As hydrogen nuclei are located within the valence shell, they are counted as a formal core in the synaptic order because hydrogen atoms only have a valence shell. For example, the valence basin accounting for a $\mathrm{C}-\mathrm{H}$ bond is labeled $\mathrm{V}(\mathrm{C}, \mathrm{H})$ and is called a protonated disynaptic basin. The valence shell of an atom $\mathrm{A}$ in a molecule is the union of the valence basins whose label lists contain the element symbol A.

The basin populations are calculated by integrating the one electron density over the basin volumes:

$$
\bar{N}\left(\Omega_{i}\right)=\int \rho(\mathbf{r}) d \mathbf{r}
$$

$\Omega_{i}$

As the basins populations are not independent $\left(\sum_{i} \bar{N}\left(\Omega_{i}\right)=N\right)$, the elements of the covariance matrix of the basin populations:

$$
\left\langle\operatorname{cov}\left(\Omega_{i}, \Omega_{j}\right)\right\rangle=\iint_{\Omega_{i} \Omega_{j}} \pi\left(\mathbf{r}_{1}, \mathbf{r}_{2}\right) d \mathbf{r}_{1} d \mathbf{r}_{2}-\bar{N}\left(\Omega_{i}\right) \bar{N}\left(\Omega_{j}\right)
$$

provide pieces of information on the electron delocalization and, in particular, can be used to build up a reliable simplified representation in terms of weighted resonance structures [14].

Within the context of the ELF analysis, the concept of domain is very important since it enables to define chemical units within a system and to characterize the valence domains belonging to a given chemical unit. The sole mathematical properties of the gradient dynamical system do not provide the whole set of definitions necessary to describe the bonding in molecules; therefore, some other mathematical approaches are required for this purpose. Mezey has introduced the topological concept of domain in Chemistry to recognize functional groups within organic molecules [15]. Generalized to ELF isovalues, this concept has proved to be an efficient "generator" of clear definitions. Any subset of the molecular space bounded by an external closed isosurface $\eta(\mathbf{r})=f$ is a domain. An $f$-localization domain is such a subset with the restriction that each point satisfies $\eta(\mathbf{r})>f$. A localization domain surrounds at least one attractor, in this case, it is called irreducible. If it contains more than one attractor, it is reducible. An irreducible domain is a subset of a basin whereas a reducible one is the union of subsets of different basins. Except for atoms and linear molecules, the irreducible domains are always filled volumes whereas the reducible ones can be either filled volumes or hollowed volumes. On increasing the value of $\eta(\mathbf{r})$ defining the bounding isosurface, a reducible domain splits into several domains, each of them containing less attractors than the parent domain. The reduction of localization occurs at turning points that are critical points of index 1 located on the separatrix of two basins involved in the parent domain. Ordering these turning points (localization nodes) by increasing $\eta(\mathbf{r})$ enables to build tree-diagrams reflecting the hierarchy of the basins. Three types of domains can be distinguished according to the nature of the attractors they encompass. A core domain contains the core attractor(s) of a given atom, a valence domain contains only valence attractors, and a composite domain contains both valence and core basins. For any system there exist low values $\eta(\mathbf{r})=f$ defining a unique composite parent domain. The successive reductions of localization will split this parent domain. Every child, which is a composite domain, corresponds to one or more chemical species. A chemical unit is then the union of the basins of the last appearing composite domain of a branch provided it is a filled volume.

In addition to the computation of the population of a basin, it has been recently shown [16] that the ELF topological analysis can also be used in the framework of a distributed moments analysis as was done for AIM [17]. That way, the $M_{0}(\Omega)$ monopole term corresponds to the opposite of the population:

$$
M_{0}(\Omega)=-\int_{\Omega} \rho(\mathbf{r}) d \tau
$$

The first moments or dipolar polarization components of the charge distribution are defined by three-dimensional integrals for a given basin $\Omega$ according to:

$$
\begin{aligned}
& \boldsymbol{M}_{1, x}(\Omega)=-\int_{\Omega}\left(x-X_{c}\right) \rho(\mathbf{r}) d \tau \\
& M_{1, y}(\Omega)=-\int_{\Omega}\left(y-Y_{c}\right) \rho(\mathbf{r}) d \tau
\end{aligned}
$$




$$
\boldsymbol{M}_{1, z}(\Omega)=-\int_{\Omega}\left(z-Z_{\mathrm{c}}\right) \rho(\mathbf{r}) d \tau
$$

where $X_{c}, Y_{c}$, and $Z_{c}$ are the Cartesian coordinates of the basin centres.

The five second-moment spherical tensor components can also be calculated and are defined as the quadrupolar polarization terms. They can be seen as the ELF basin equivalents to the atomic quadrupole moments introduced by Popelier in the case of an AIM analysis [17]:

$$
\begin{gathered}
M_{2, z z}(\Omega)=-\frac{1}{2} \int_{\Omega}\left(3\left(z-Z_{c}\right)^{2}-\mathbf{r}^{2}\right) \rho(\mathbf{r}) d \tau \\
M_{2, x^{2}-y^{2}}(\Omega)=-\frac{\sqrt{3}}{2} \int_{\Omega}\left[\left(x-X_{c}\right)^{2}-\left(y-Y_{c}^{2}\right)\right] \rho(\mathbf{r}) d \tau \\
M_{2, x y}(\Omega)=-\sqrt{3} \int_{\Omega}\left(x-X_{c}\right)\left(y-Y_{c}\right) \rho(\mathbf{r}) d \tau \\
M_{2, x z}(\Omega)=-\sqrt{3} \int_{\Omega}\left(x-X_{c}\right)\left(z-Z_{c}\right) \rho(\mathbf{r}) d \tau \\
M_{2, y z}(\Omega)=-\sqrt{3} \int_{\Omega}\left(y-Y_{c}\right)\left(z-Z_{c}\right) \rho(\mathbf{r}) d \tau \quad(7)
\end{gathered}
$$

The first- or second-moment basin magnitude is then defined as the square root of the sum of squared components:

$$
|\mathbf{M}(\Omega)|=\sqrt{\sum_{i} M_{i}(\Omega)^{2}}
$$

Thanks to the invariance of the magnitude of any multipole rank $\left(\mathrm{M}_{1}\right.$ or $\left.\mathrm{M}_{2}\right)$ with respect to the axis for a given bond or lone pair, the approach allows us to compare the dipolar or quadrupole polarization of a given basin in different chemical environments.

That way, the Distributed Electrostatic Moments based on the ELF Partition (DEMEP) allows computing of local moments located at nonatomic cen- ters such as lone pairs, $\sigma$ bonds, and $\pi$ systems. Local dipole contributions have been shown to be useful to rationalize inductive polarization effects and typical hydrogen bond interactions. Moreover, bond quadrupole polarization moments being related to a $\pi$ character enable to discuss bond multiplicities, and to sort families of molecules according to their bond order $[16,17]$.

\section{Examples of Application}

\subsection{COMPUTATIONAL METHODS}

The calculations have been performed with the Gaussian $a b$ initio code [18]. The B3LYP, PBE0 hybrid Hartree-Fock, BHLYP density functional method [19-21], or the MP2 approach have been chosen because they yield realistic enough equilibrium geometries and do not hamper the efficiency of the topological analysis. In principle, the determination of accurate values of the spectroscopic properties (such as frequency shifts corrected for anharmonicity) requires a better treatment of the intermolecular contribution of the electron correlation that is neglected in the DFT approach [22]. The evaluation of the ELF function and that of the basin properties has been carried out with the TopMoD program $[16,23,24]$ and visualized with the Amira 3.0 [25] or Molekel 4.0 [26] softwares.

\subsection{BOND ANALYSIS IN AMINOACIDS}

\subsubsection{Analyzing Amino Acids}

We recently applied the analysis of the ELF electrostatic moments to aminoacids [16].

Table I displays the magnitude of the local $\mathrm{M}_{0}$, $\mathrm{M}_{1}$, and $\mathrm{M}_{2}$ chemically intuitive distributed electrostatic moments for some basins of interest for glycine, valine, and tyrosine. We focused our attention to the basins of the amino acid $\mathrm{C}^{2} \mathrm{H}_{2}\left(\mathrm{NH}_{2}\right) \mathrm{C}^{1} \mathrm{O}^{2} \mathrm{O}^{1} \mathrm{H}$ main chain as displayed on Figure 1.

Our results reflect the transferability properties of these moments from one aminoacid to another. Indeed, the polarization magnitudes $\mathrm{M}_{1}, \mathrm{M}_{2}$, and the local dipole of the bonding basins appear very stable. These results demonstrate that amino acids share common electrostatic and electronic characteristics. Such assumption could be useful to rationalize the design of new density-based force fields $[27,28]$. 
TABLE I

Local dipole contributions and magnitude of the first and second moments of some basins of typical basins involved in the main chain $\mathrm{C}^{2} \mathrm{H}_{2}\left(\mathrm{NH}_{2}\right) \mathrm{C}^{1} \mathrm{O}^{2} \mathrm{O}^{1} \mathrm{H}$ of amino acid.

\begin{tabular}{|c|c|c|c|c|c|c|c|c|c|c|c|c|c|}
\hline \multirow[b]{2}{*}{ Amino acid } & \multicolumn{2}{|c|}{$\mathrm{V}\left(\mathrm{C}^{1}, \mathrm{O}^{1}\right)$} & \multicolumn{2}{|c|}{$\mathrm{V}\left(\mathrm{C}^{1}, \mathrm{O}^{2}\right)$} & \multicolumn{2}{|c|}{$V\left(C^{2}, N\right)$} & \multicolumn{3}{|c|}{$\mathrm{V}(\mathrm{N})$} & \multicolumn{3}{|c|}{$\mathrm{V}\left(\mathrm{O}^{2}\right)$} & \multirow{2}{*}{$\frac{\text { total }}{|\mu|^{c, d}}$} \\
\hline & $\left|M_{1}\right|$ & $\left|M_{2}\right|$ & $\left|\mathrm{M}_{1}\right|$ & $\left|M_{2}\right|$ & $\left|M_{1}\right|$ & $\left|M_{2}\right|$ & $\left|M_{1}\right|$ & $\left|M_{2}\right|$ & $|\mu|$ & $\left|M_{1}\right|$ & $\left|\mathrm{M}_{2}\right|$ & $|\mu|$ & \\
\hline Glycine $^{\mathrm{a}, \mathrm{b}}$ & $\begin{array}{c}0.255 \\
(0.247)\end{array}$ & $\begin{array}{c}1.249 \\
(1.221)\end{array}$ & $\begin{array}{c}0.052 \\
(0.050)\end{array}$ & $\begin{array}{c}0.257 \\
(0.270)\end{array}$ & $\begin{array}{c}0.183 \\
(0.207)\end{array}$ & $\begin{array}{c}0.166 \\
(0.177)\end{array}$ & $\begin{array}{c}0.952 \\
(1.055)\end{array}$ & $\begin{array}{c}0.125 \\
(0.100)\end{array}$ & $\begin{array}{c}11.6 \\
(12.0)\end{array}$ & $\begin{array}{c}3.308 \\
(2.955)\end{array}$ & $\begin{array}{c}2.446 \\
(2.136)\end{array}$ & $\begin{array}{c}11.6 \\
(11.5)\end{array}$ & $\begin{array}{c}0.50 \\
(0.48) \\
0.48 \\
(0.46)\end{array}$ \\
\hline Valine $^{a}$ & 0.281 & 1.241 & 0.059 & 0.256 & 0.177 & 0.173 & 0.931 & 0.167 & 11.5 & 3.296 & 2.417 & 12.2 & $\begin{array}{c}0.55 \\
(0.55)\end{array}$ \\
\hline Tyrosine $^{a}$ & 0.270 & 1.210 & 0.059 & 0.268 & 0.177 & 0.172 & 0.929 & 0.161 & 11.5 & 3.286 & 2.454 & 12.0 & $\begin{array}{c}0.95 \\
(0.92)\end{array}$ \\
\hline
\end{tabular}

a Optimized at B3LYP/6-31+G(d,p) level of computation.

b The values given in parentheses correspond to a single point calculation at the B3LYP/Aug-cc-pVTZ level of computation.

c Total molecular dipole of the amino acid in a.u.

${ }^{d}$ The values given in parentheses are obtained from the SCF calculation provided by the Gaussian 03 software.

It is also important to point out that Table I also compares the topological moments for the glycine molecule as obtained from the $6-31+G(d, p)$ and the aug-cc-pVTZ basis sets. The magnitude of the topological moments is shown to be quite stable with these two different basis sets. In contrast to the well-known basis set dependence of the Mulliken partition, the topological partition appears then less sensitive to basis sets.

\subsubsection{Description of the CN Peptidic Bond}

The nature of the peptidic $\mathrm{CN}$ bond has been examined using the ELF localization function on the smallest model system, namely $\mathrm{N}$-methylacetamide (NMA) $[29,30]$. One of the essential issues for this system deals with the extension and the nature of the resonance between $\mathrm{N}$ and $\mathrm{CO}$ [31], as illustrated in Figure 2. The evolution of the relative weight of
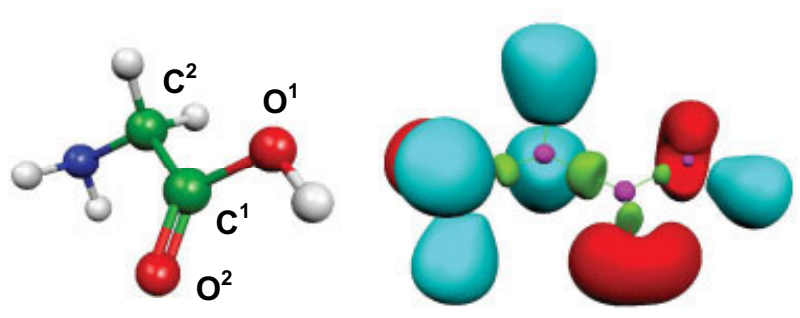

FIGURE 1. ELF localization domains in glycine. [Color figure can be viewed in the online issue, which is available at www.interscience.wiley.com.] these two forms on rotation along the peptidic bond is indeed essential to the evaluation of the rotation barrier as well as to understand the variations of the electronic structure at $\mathrm{N}$.

The isomerization pathway has been investigated by carrying out a relaxed potential energy surface along the $\mathrm{CH}_{3}-\mathrm{N}-\mathrm{C}(\mathrm{O})-\mathrm{CH}_{3}$. The results are gathered in Table II (the computations reported in this Part has been performed at the MP2 level of theory using the $6-311+\mathrm{G}^{* *}$ basis sets for all atoms). In the planar structures, namely the cis $\left(0^{\circ}\right)$ and the trans $\left(180^{\circ}\right)$ conformers, the $\mathrm{N}$ lone pair $\mathrm{LP}(\mathrm{N})$ is found to be depleted by more than 1 electron when compared to the non delocalized structure at $90^{\circ}$. Altogether, the population of the $\mathrm{V}(\mathrm{N}, \mathrm{C})$ basin corresponding to the $\mathrm{N}-\mathrm{C}(\mathrm{O})$ bond is significantly larger in planar structures, which is in line with a partial double bond character. This delocalization is associated, as expected, to a significant shortening of the $\mathrm{N}-\mathrm{C}$ distance and to a rotation barrier close to $10 \mathrm{kcal} / \mathrm{mol}$.

The amplitude of the delocalization was evaluated by computing the relative weight of the two<smiles>CC(=O)[NH+](C)C</smiles>

FIGURE 2. Two potential resonant structures for trans-NMA. 
TABLE II

NMA energetic ( $\mathrm{kcal} / \mathrm{mol}$ with respect to the $180^{\circ}$ isomer), geometric (Å), and ELF population (in electron, see text for symbols) properties as a function of the $\mathrm{CH}_{3}-\mathrm{N}-\mathrm{C}(\mathrm{O})-\mathrm{CH}_{3}$ angle (degrees).

\begin{tabular}{rrcccc}
\hline Angle & ENERGY & $\begin{array}{c}\mathrm{N}-\mathrm{C} \\
\text { distance }\end{array}$ & $\mathrm{LP}(\mathrm{N})$ & $\mathrm{V}(\mathrm{N}, \mathrm{C})$ & $\omega(\mathrm{N}-\mathrm{C})$ \\
\hline 0 & 2.6 & 1.37 & 1.00 & 2.15 & 0.63 \\
30 & 3.9 & 1.38 & 1.67 & 2.31 & 0.84 \\
60 & 6.2 & 1.40 & 1.97 & 2.09 & 0.97 \\
90 & 11.7 & 1.42 & 2.15 & 1.96 & 1.05 \\
120 & 7.9 & 1.40 & 1.91 & 2.12 & 0.95 \\
150 & 1.5 & 1.38 & 1.64 & 2.34 & 0.82 \\
180 & 0.0 & 1.37 & 1.10 & 2.85 & 0.56
\end{tabular}

$\omega(\mathrm{N}-\mathrm{C})$ is the weight of the singly bonded resonant form in the case of a two-state description of the $\mathrm{N}-\mathrm{C}$ bond.

structures, considering that the total population $\mathrm{LP}(\mathrm{N})+\mathrm{V}(\mathrm{NC})$ is constant. The weight of the singly bonded resonant forms is then evaluated as:

$$
w(N-C)=\frac{2 \cdot L P(N)}{L P(N)+V(N, C)}
$$

In these conditions, the nondelocalized form is found, as expected, to be the only structure in the $90^{\circ}$ form. As nearly 50\% share between the two isomers is then retrieved for the planar structures.

A similar approach to the evaluation of the multiple bond character was recently used to evaluate the delocalization of the pyrrole nitrogen lone pair on electron acceptor substituents [32]. In the case of an inductive attractor substituent only (sulfonate group $\mathrm{SO}_{2} \mathrm{Me}$ ), no variation of the N-S population is observed. In the case of a mesomeric attractor group (carbamate group $\mathrm{CO}_{2} \mathrm{Me}$ ), a significant decrease ( $0.21 \mathrm{e}$ ) of the $\mathrm{N}-\mathrm{C}$ population takes place on rotation of the group by $90^{\circ}$.

\subsection{NCO DATIVE BOND IN ASPARTIC PROTEASE INHIBITOR}

The physical origin of the noticeably weak N... CO bond formed between a nitrogen from a tertiary amino-group and a formaldehyde group requires a special attention. Indeed, this interaction was identified to be important in many biochemical systems [33] and has been recently shown to be essential to the mechanism of action of a new class of aspartic proteases inhibitors [34]. Because these enzymes play a pivotal role in the replication of the HIV virus, the stakes in the design of inhibitors mimicking properties (electronic and steric) of the transition-state structure are high. Several experimental and theoretical studies have shown the surprising sensitivity of the $\mathrm{N}-\mathrm{C}$ distance to the environment effects (solvation) [35 and references therein]. However, a recent theoretical work [36] attempted to clear up the nature of the NCO interaction by means of the ELF analysis. The topological analysis has revealed an unusual dative bond formation from a long $\mathrm{N}-\mathrm{C}$ distance $\left(d_{\mathrm{NC}}>2.5 \AA\right)$ to a short $\mathrm{N}-\mathrm{C}$ distance $\left(d_{\mathrm{NC}}<2 \AA\right)$. Moreover, a correlated wave function analysis has confirmed the nondispersive character of this interaction. Figure 3 illustrates the localization domains of the bimolecular system $\mathrm{N}(\mathrm{Me})_{3} \mathrm{H}_{2} \mathrm{CO}$ for a large and a short $\mathrm{N}-\mathrm{C}$ distance obtained at the B3LYP/6$31+G(d)$ level of theory.

As displayed in Figure 3 (left), at large $\mathrm{N}-\mathrm{C}$ distances, a single monosynaptic basin $\mathrm{V}(\mathrm{N})$ is observed near to the nitrogen core, which suggests a pure electrostatic nature for the N. . CO interaction. In contrast, as the $\mathrm{N}-\mathrm{C}$ distance shortens, the nitrogen lone pair is involved in the dative $\mathrm{N}-\mathrm{C}$ bond formation and a disynaptic basin $\mathrm{V}(\mathrm{C}, \mathrm{N})$ is observed (see Fig. 3, right). A density transfer toward the carbonyl group is observed at short $\mathrm{N}-\mathrm{C}$ distances but this transfer remains surprisingly small with respect to the traditional $\mathrm{N}^{+}-\mathrm{C}-\mathrm{O}^{-}$ bond picture resulting from the charge transfer $n_{\mathrm{N}} \rightarrow \pi^{*} \mathrm{CO}[35(\mathrm{~d}, \mathrm{e})$ and references therein]. Moreover, the ELF population analysis reveals a large charges separation into the carbonyl moiety. Thus, the bond scheme appears consistent with an unusual picture $\mathrm{N} \ldots \mathrm{C}^{+}-\mathrm{O}^{-}$described by an enhancement of the $\mathrm{CO}$ ionic character due to the polarization effect of the near nitrogen lone pair. The solvating environment has a main stabilizing role of this ionic configuration, which explains why the short $\mathrm{N}-\mathrm{C}$ distances are preferred in a polar environment. Moreover, at very short $\mathrm{N}-\mathrm{C}$ distances $\left(d_{\mathrm{NC}}<1.7 \AA\right)$ the protic environment is able to enhance the ionic $\mathrm{C}^{+}-\mathrm{O}^{-}$configuration because a small charge transfer is observed from the $\mathrm{C}-\mathrm{O}$ bond to the water molecules. Thus, by cumulative effect, the covalent bonding basin $\mathrm{V}(\mathrm{C}, \mathrm{O})$ is firmly depopulated and the $\mathrm{C}-\mathrm{O}$ bond is weakened.

These results are supported by the chemical analysis of local dipolar and quadrupolar moments of the $\mathrm{C}-\mathrm{O}$ bonding basin [16]. Indeed, at large $\mathrm{N}-\mathrm{C}$ distances, a strong quadrupolar polarization (1.43 a.u.) of the bonding basin $\mathrm{V}(\mathrm{C}, \mathrm{O})$ is observed 


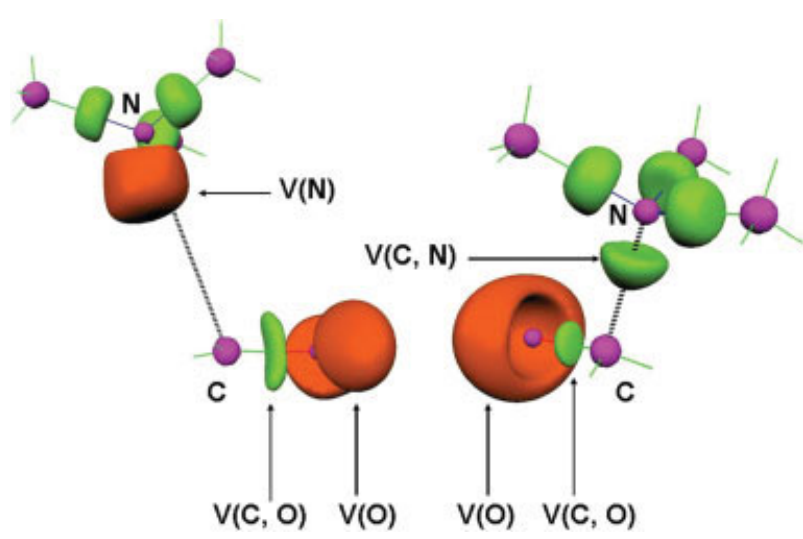

FIGURE 3. ELF localization domains of the bimolecular system $\mathrm{N}(\mathrm{Me}){ }_{3} \mathrm{H}_{2} \mathrm{CO}$ for two $\mathrm{N}-\mathrm{C}$ distances: $d_{\mathrm{N}-\mathrm{C}}$ $=3.0 \AA$ (left) and $d_{\mathrm{N}-\mathrm{C}}=1.63 \AA$ (right). Basin code color: magenta: core; green: bonding; and red: nonbonding. The pronotated basins $\mathrm{C}-\mathrm{H}$ and $\mathrm{N}-\mathrm{H}$ have been omitted for clarity. [Color figure can be viewed in the online issue, which is available at www.interscience. wiley.com.]

while a smaller value ( 0.42 a.u.) is observed at short $\mathrm{N}-\mathrm{C}$ distances. As expected for the long $\mathrm{N}-\mathrm{C}$ distances, these results reveal the strong $\pi$ character of the $\mathrm{C}-\mathrm{O}$ bond and the strong $\mathrm{sp}^{2}$ hybridation of the carbon atom. Conversely, at short $\mathrm{N}-\mathrm{C}$ distances, the local moments analysis indicates a weak $\pi$ character of the $\mathrm{C}-\mathrm{O}$ bond in agreement with the $\mathrm{N} \ldots \mathrm{C}^{+}-\mathrm{O}^{-}$bond picture.

\subsection{CYCLISATIONS INVOLVING SULFUR ATOMS IN DIPEPTIDIC CATION RADICALS}

Two-center-three-electron (2c-3e) bonded radicals have attracted considerable attention in recent years. They play an important role as reaction intermediate during electron transfer processes, and particularly for those occurring in biological media. Initially introduced by Pauling [37] within the valence bond (VB) framework, the 2c-3e bonds owe their stability to a resonance between two Lewis structures that are mutually related by charge transfer as shown below in the case of cation radicals:

$$
\cdot \mathrm{A}^{+} \mathrm{B}: \leftrightarrow{ }^{\bullet} \mathrm{B}^{+} \mathrm{A}:
$$

Therefore, the binding energy is maximal for $\mathrm{A}=\mathrm{B}$ and it is weakened with the increase of the ionization potential difference between $\mathrm{A}$ and $\mathrm{B}$. The $2 \mathrm{c}-3 \mathrm{e}$ bond has been investigated by the ELF topological analysis in numerous anionic, cationic as well as neutral radical [33]. Within this framework, it is characterized by the absence of a disynaptic basin between the A and B cores and by a common separatrix limiting the $\mathrm{V}(\mathrm{A})$ and $\mathrm{V}(\mathrm{B})$ monosynaptic basins, in which is located the major part of the spin density. The strongest $2 \mathrm{c}-3 \mathrm{e}$ bonds thus present a well-balanced sharing of the spin density. The electron fluctuation, which is a central phenomenon in these types of bonds, occurs mainly between the lone pairs of the two heteroatoms. The topological signature of this electron delocalization is the covariance of the $\mathrm{V}(\mathrm{A})$ and $\mathrm{V}(\mathrm{B})$ basin population, which is rather large. This approach provides unambiguous descriptors of the $\mathrm{A} . \mathrm{B}$ in agreement with the VB method. It is also possible to define a Core Valence Bifurcation (CVB) index by considering the value of the ELF at the index 1 critical point of the $V(A) / V(B)$ separatrix. This index decreases with the increase of the ionization potential difference between the two moieties in the case of cation radicals.

The technique outlined earlier has been successfully applied to three dipeptidic cation radicals, namely the Met-Gly, Gly-Met, and Met-Met (Met = methionine, Gly = Glycine) for which there is an experimental evidence of rather strong $S-X(X=N$, $\mathrm{O}, \mathrm{S})$ interactions. For each cation radical, several local minima have been obtained on the potential energy surface, corresponding to the formation of intramolecular $[\mathrm{S} . . \mathrm{N}]^{+},[\mathrm{S} . . \mathrm{OO}]^{+}$, and $[\mathrm{S} . . \mathrm{S}]^{+}$ bond by cyclization with 5,6 , or 7 atoms. The ELF localization domains of these cation radicals are displayed in Figure 4 in the case of S.: $\mathrm{X}^{+}$intramolecular bond for $\mathrm{X}=\mathrm{N}$ and $\mathrm{S}$. The topological analysis confirms the existence of a $2 c-3 e$ bond. For example, the CVB indexes are positive and greater for $S . \therefore S^{+}$than for $S: \mathrm{N}^{+}$. In addition, the large covariance matrix elements between $\mathrm{V}(\mathrm{S})$ and $\mathrm{V}(\mathrm{X})$
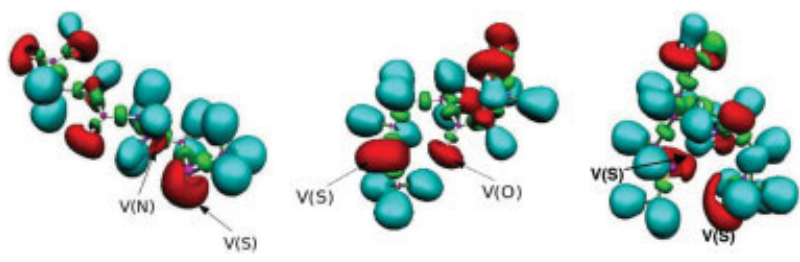

FIGURE 4. ELF localization domains $(\eta=0.8)$ of the Met-Gly (left), Gly-Met (center), and Met-Met (right) cation radicals showing the location of the $\mathrm{S}$. . XN 2c-3e bond. [Color figure can be viewed in the online issue, which is available at www.interscience.wiley.com.] 


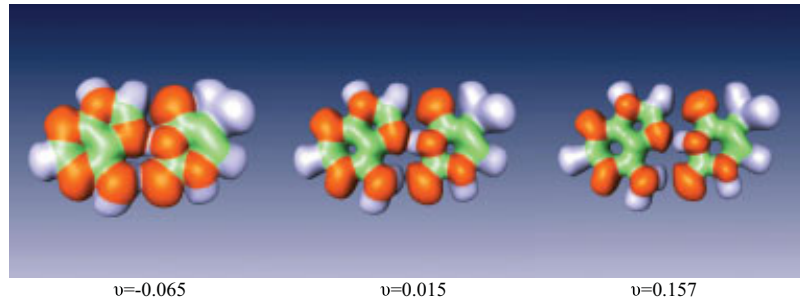

FIGURE 5. Adenine-thymine pair localization domains. From left to right the bounding isosurface values are $\eta=0.095, \eta=0.150$, and $\eta=0.240$.

provide an additional support to this interpretation [38]. On the contrary, for $\mathrm{X}=\mathrm{O}$, even though there is no $\mathrm{V}(\mathrm{S}, \mathrm{O})$ disynaptic basin, the spin density is almost entirely located within the $\mathrm{V}(\mathrm{S})$ basin and the CVB index is found negative. Thus, the S. . . $\mathrm{O}^{+}$ intramolecular bond has a electrostatic character, as already pointed out for the $\mathrm{S} . . \mathrm{O}^{+}$intermolecular bond in model systems $\mathrm{RCH}_{3} \mathrm{~S} \ldots \mathrm{OH}_{2}^{+}(\mathrm{R}=$ $\left.\mathrm{H}, \mathrm{CH}_{3}\right)[39]$.

\subsection{HYDROGEN BONDS BETWEEN DNA BASES}

Within the ELF analysis framework, an hydrogen bond is characterized by the presence of a protonated valence basin sharing a separatrix with at least another valence basin which does not participate to the same atomic valence shell [40]. The protonated valence basin is generally a disynaptic one, except for very strong hydrogen bonds such as in the FHF complex where it is monosynaptic [41] whereas the other valence basin is monosynaptic (H-bond involving a lone pair), disynaptic (H-bond involving a bond, ex: $\mathrm{FH}(\mathrm{CH})$ or protonated disynaptic in the case of the so-called dihydrogen bond [42]. According to the definition of a chemical object given above, a hydrogen-bonded complex can be considered either as a single molecular species or as an assembly of molecules. In the case of standard hydrogen bonds, the bridge involves the protonated valence basin $\mathrm{V}(\mathrm{A}, \mathrm{H})$ and another valence basin in the valence shell of center $B$. When the value of $E L F$ at the index 1 critical point on the separatrices of $V(B, \ldots)$ and $C(B)$ is greater than the value at the corresponding critical point between $\mathrm{V}(\mathrm{A}, \mathrm{H})$ and $V(B, \ldots)$, there are two chemical units and therefore the complex should be considered as an assembly of molecules. On the contrary, the valence shells of the atoms of the two moieties belong to a single valence shell, thus enabling to consider the complex as a molecule. Therefore, the difference of these two quantities has been considered as a measure of the hydrogen bond strength [41]. The corevalence bifurcation (CVB) index:

$$
V(\mathrm{AHB})=\eta_{\mathrm{vv}}(\mathrm{AHB})-\eta_{\mathrm{cv}}(B)
$$

is negative in the case of weak complexes and positive in stronger ones. For a given proton donor moiety, almost linear correlations have been found between the core-valence bifurcation indexes and the complexation energies or $\mathrm{AH}$ stretching frequencies [41]. The use of the index is particularly appealing for complexes linked by several hydrogen bonds. In such cases, as mentioned by Gutierrez-Oliva et al. [43], the "electron density and hence the topological CVB indexes are probably more accurate than any of the other possibilities (BEBO resolution or frequency shifts)." Figures 5 and 6 display the ELF localization domains of the adeninethymine and guanine-cytosine base pairs calculated with isosurface values showing the valence-valence saddle point of each individual hydrogen bond. In the adenine-thymine pair, the CVB indexes of the $\mathrm{CH} \cdot{ }^{\circ} \mathrm{O}, \mathrm{NH}_{2} \cdot{ }^{\circ} \mathrm{O}$, and $\mathrm{NH} \cdot \cdot \mathrm{N}$ hydrogen bonds are, respectively, $-0.065,0.015$, and 0.157 . In the guanine-cytosine pair, the $\mathrm{NH} \cdot{ }^{\mathrm{N}}$ hydrogen bond is also the strongest one. These results are in good agreement with the order of the hydrogen bond experimental lengths in each pair as discussed by Fonseca-Guerra et al. [44, 45].

\subsection{OXYGENATED DINUCLEAR COPPER ENZYME MODELS}

Dinuclear copper metalloproteins are widely spread enzymes that are present in almost all living organisms from plants to animals (see Refs. 46-48 and references herein). Their capabilities encompass molecular oxygen transport (hemocyanin) or

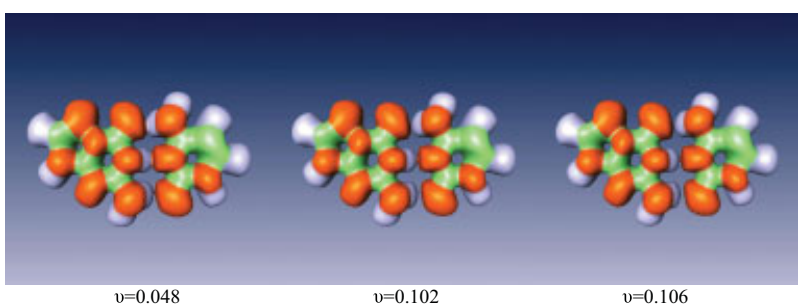

FIGURE 6. Guanine-cytosine pair localization domains. From left to right the bounding isosurface values are $\eta=0.125, \eta=0.180$, and $\eta=0.190$. 

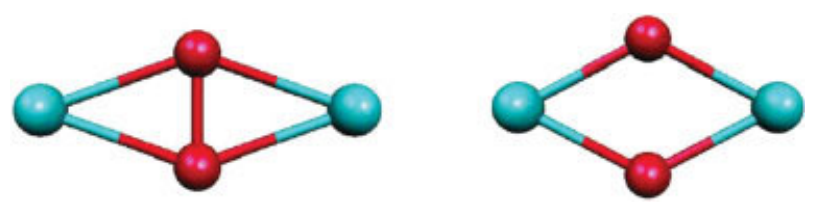

FIGURE 7. $\left[\mathrm{Cu}_{2}\left(\mu-\eta^{2}: \eta^{2}-\mathrm{O}_{2}\right)\right]^{2+}(\mathrm{A})$ and $\left[\mathrm{Cu}_{2}(\mu-\right.$ $\left.\mathrm{O}_{2}\right]^{2+}$ (B) structures. [Color figure can be viewed in the online issue, which is available at www.interscience. wiley.com.]

oxidation (tyrosinase). Two principal arrangements of the oxygenated $\mathrm{Cu}_{2} \mathrm{O}_{2}$ central core are observed as displayed on Figure 7 [48]: a first one, $\left[\mathrm{Cu}_{2}\left(\mu-\eta^{2}\right.\right.$ : $\left.\left.\eta^{2}-\mathrm{O}_{2}\right)\right]^{2+}$ (denoted structure A), is associated with an $\mathrm{O}-\mathrm{O}$ bond and the second one, $\left[\mathrm{Cu}_{2}\left(\mu-\mathrm{O}_{2}\right)\right]^{2+}$ (structure B), is characterized by an absence of $\mathrm{O}-\mathrm{O}$ bond and by a significantly shorter $\mathrm{Cu}-\mathrm{Cu}$ distance.

In two recent studies $[47,48]$, some of us have shown that the two structures are clearly distinguished by the ELF topological analysis. As can be seen on Figure 8, structure A is characterized by a strong $\mathrm{O}-\mathrm{O}$ covalent bond and exhibits a small $\mathrm{Cu} \rightarrow \mathrm{O}$ charge transfer. In contrast, structure $\mathrm{B}$ is described by two $\mathrm{V}(\mathrm{O})$ lone pair basins and by a stronger $\mathrm{Cu} \rightarrow \mathrm{O}$ charge transfer.

In agreement with previous studies, we have found an influence of the level of calculation. Such influence can be studied by defining weights for mesomeric structures [14]. For example, concerning the $\mathrm{Cu}_{2} \mathrm{O}_{2}$ core $\mathrm{A}$ arrangement, we can define three resonating structures according to the $\mathrm{O}_{2}$ nature and $\mathrm{Cu}$ oxydation state.

$$
\begin{aligned}
\omega_{1}:\left[\mathrm{Cu}_{2}^{I}\left(\mu-\eta^{2}: \eta^{2}-\mathrm{O}_{2}\right)\right]^{2+} ; \omega_{2}:\left[\mathrm { Cu } ^ { \mathrm { I } } \mathrm { Cu } ^ { \mathrm { II } } \left(\mu-\eta^{2}: \eta^{2}\right.\right. \\
\left.\left.-\mu \mathrm{O}_{2}\right)^{-}\right]^{2+} ; \omega_{3}:\left[\mathrm{Cu}_{2}^{\mathrm{II}}\left(\mu-\eta^{2}: \eta^{2}-\mathrm{O}_{2}\right)^{2-}\right]^{2+}
\end{aligned}
$$

It is then also possible to introduce another useful quantity denoted $\delta q$ which corresponds to the net electronic charge transfer from the copper atoms to their neighbors: $\delta q=Z(C u)-\bar{N}[C(C u)]$. The first structure $\omega_{1}$ corresponds then to an interaction between two $\mathrm{Cu}^{\mathrm{I}}$ atoms and the $\mathrm{O}_{2}$ closed-shell singlet molecule $\left({ }^{1} \Sigma_{\mathrm{g}}^{+}\right) \cdot \omega_{1}$ corresponds to a formal charge transfer $\delta q=1$. The second structure $\omega_{2}$ is an interaction between a $\mathrm{Cu}^{\mathrm{I}} / \mathrm{Cu}^{\mathrm{II}} \mathrm{Cu}_{2} \mathrm{O}_{2}$ core and the superoxide doublet state $\left(\mathrm{O}_{2}\right)^{-}\left({ }^{2} \Pi_{\mathrm{gi}}\right)$. $\omega_{2}$ corresponds to $\delta q=1.50$. The last structure $\omega_{3}$ corresponds to an interaction between two $\mathrm{Cu}^{\mathrm{II}}$ cations and a closed-shell singlet peroxide dianion $\left(\mathrm{O}_{2}\right)^{2-}$ $\left({ }^{1} \Sigma_{\mathrm{g}}^{+}\right)$. The $\omega_{3}$ structure is consistent with $\delta \mathrm{q}=2$.
Using the covariance matrix [14] and the ELF population of the $\mathrm{O}-\mathrm{O}$ bond basin [48], we can then assign a weight to any of these structures at the DFT level:

B3LYP Closed-Shell Singlet $\omega_{1}(72 \%) \omega_{2}(0 \%) \omega_{3}(28 \%)$ PBE0 Open shell Singlet $\quad \omega_{1}(53 \%) \omega_{2}(32 \%) \omega_{3}(15 \%)$ B3LYP Open shell Singlet $\omega_{1}(43 \%) \quad \omega_{2}(39 \%) \quad \omega_{3}(18 \%)$

It is possible to correlate $\delta \mathrm{q}$ to the $\mathrm{O}-\mathrm{O}$ bond length as displayed on Figure 9.

Adding the formal structures $\omega_{1}(\delta q=1.0), \omega_{2}$ $(\delta q=1.5)$, and $\omega_{3}(\delta q=2.0)$, to the ELF results, we obtain an almost perfect correlation $\left(r^{2}=0.99\right)$. It is then possible to extrapolate the CASSCF $\delta q$ value according the $\mathrm{O}-\mathrm{O}$ CASSCF optimized structure distance. Indeed, CASSCF values must be extrapolated as the covariance matrix is only approximated at this level. We did so (see Ref. 48 for details) and found the following weights for the resonating structures:

$$
\text { CASSCF } \quad \omega_{1}(6 \%) \quad \omega_{2}(7 \%) \quad \omega_{3}(87 \%)
$$

This result means that, indeed, the electronic structure of the A antiferromagnetic complex is well described at the CASSCF level because of its multideterminantal nature allowing a correct treatment of nondynamical correlation effects. Unfortunately, dynamic correlation is missing explaining the overestimation of the $\mathrm{O}-\mathrm{O}$ bond length. On the opposite, the single determinant DFT broken symmetry method exhibits a $\mathrm{O}-\mathrm{O}$ bond length closer

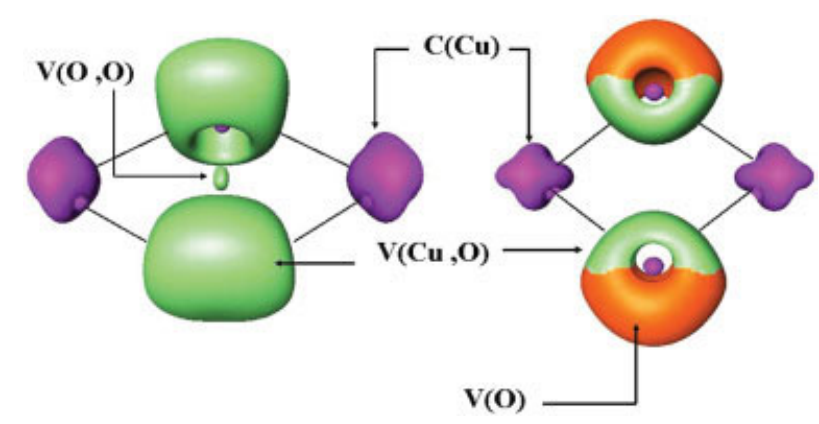

FIGURE 8. ELF localization domains of (A) $\left[\mathrm{Cu}_{2}\left(\mu-\eta^{2}\right.\right.$ : $\left.\left.\eta^{2}-\mathrm{O}_{2}\right)\right]^{2+}$ (left) and (B) $\left[\mathrm{Cu}_{2}(\mu-\mathrm{O})_{2}\right]^{2+}$ (right) structures optimized at the B3LYP/DZVP2 level. The ELF isosurfaces are $E L F=0.75$. Basin code color: magenta: core; green: bonding; and red: nonbonding. Reproduced by permission of Elsevier. [Color figure can be viewed in the online issue, which is available at www.interscience. wiley.com.] 


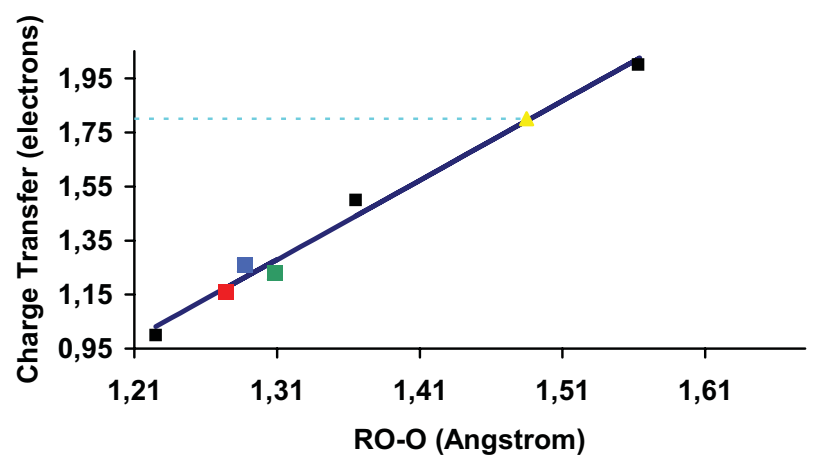

FIGURE 9. Charge transfer quantity $(\delta q)$ as a function of the O-O distance for the A structures obtained using DFT. Color code: red for closed-shell B3LYP; blue for open-shell singlet B3LYP; and green for open-shell singlet PBE0. The formal structures $\omega_{1}(\delta q=1.0), \omega_{2}$ $(\delta q=1.5)$, and $\omega_{3}(\delta q=2.0)$ are also displayed (black squares). The yellow dot is the simulated value for the CASSCF case. The line corresponds to the linear regression $\left(r^{2}=0.99\right)$. [Color figure can be viewed in the online issue, which is available at www.interscience. wiley.com.]

to CASPT2 but only offers a partial recovery of the antiferromagnetic coupling. Indeed, the functional dependant (i.e., B3LYP gives different results compared to PBE0) self-interaction error induces spin delocalization effects on the oxygen atoms.

We can also describe structure B in the DFT case by mixing the two following structures: $\omega_{4}\left(\mathrm{Cu}^{\mathrm{I}}\right.$ $\left.\left.\mathrm{Cu}^{\mathrm{II}}(\mu-\mathrm{O})_{2}{ }^{-}\right]^{2+}\right)$ and $\omega_{5}\left(\left[\mathrm{Cu}_{2}{ }^{\mathrm{II}}\left(\mu-\mathrm{O}^{-}\right)_{2}\right]^{2+}\right)$, according to the ELF population analysis. The $\omega_{4}$ configuration describes a partial copper-oxygen coupling in correlation with $\delta q=1.5$. The $\omega_{5}$ structure corresponds to a perfect antiferromagnetic configuration. The calculated weights in the open-shell singlet B3LYP case provides a distribution of $78 \%$ for $\omega_{4}$ and $22 \%$ for $\omega_{5}$. This result is in agreement with the idea of a partial coupling. CASSCF should prefer the $\omega_{5}$ configuration in agreement with the calculated CASSCF corresponding AIM charges and with a simple inspection of the wave-function. Indeed, the diagonal elements of the final one-electron density matrix reflect an occupation close to 1 for the molecular orbitals localized on copper and oxygen atoms. In conclusion, the B-type electronic structure shows a higher copper oxidation degree according to a consistent antiferromagnetic coupling.

These results also illustrate the fact that the interconversion process from structure A to the B binding mode is carried out by a decrease of the popu- lations of the $\mathrm{V}(\mathrm{Cu}, \mathrm{O})$ and $\mathrm{V}\left(\mathrm{O}_{1}, \mathrm{O}_{2}\right)$ "bond" basins over the monosynaptic $\mathrm{V}(\mathrm{O})$ oxygen "lone pair" basins. In other word, if we start from $\mathrm{A}$ and increase the $\mathrm{O}-\mathrm{O}$ bond distance, we will see electrons moving outside the bond basin as they tend to reform lone pairs basins specific of the B form. This process appears very sensitive to the methodology, the oxygen lone pairs being subjected to large selfinteraction errors at the DFT level.

We then have added supplementary ligands (denoted as $\mathrm{L}$ ) to the central $\mathrm{Cu}_{2} \mathrm{O}_{2}$ core in order to build a more realistic model of tyrosinase [47, 48]. As can be seen from Figure 10 the A-L complexes, which are the most stable at the DFT level, show important topological modifications compared to original $\mathrm{Cu}_{2} \mathrm{O}_{2}$ core electronic structure: a more complex three center bond is observed through two $\mathrm{V}\left(\mathrm{Cu}_{1}, \mathrm{O}, \mathrm{Cu}_{2}\right)$ trisynaptic basins. An interesting point is that such basins are no longer located between $\mathrm{Cu}$ and $\mathrm{O}$ atoms. The final $\mathrm{Cu}-\mathrm{O}-\mathrm{Cu}$ basins are spatially rotated being above and bottom the molecular $\mathrm{Cu}_{2} \mathrm{O}_{2}$ plan.

We tested two ligand models: $\mathrm{NH}_{3}$ and imidazole $(\mathrm{ImH}) . \mathrm{NH}_{3}$ can be distinguished from the imidazole ligand as they exhibit a weaker $\mathrm{Cu} \rightarrow \mathrm{O}$ charge transfer and a less covalent interaction with the central metallic core. Moreover, the ImH ligand model presents a modification of the complex symmetry known as the butterfly effect $[46,47]$. At the DFT level, the competitive self interaction effects

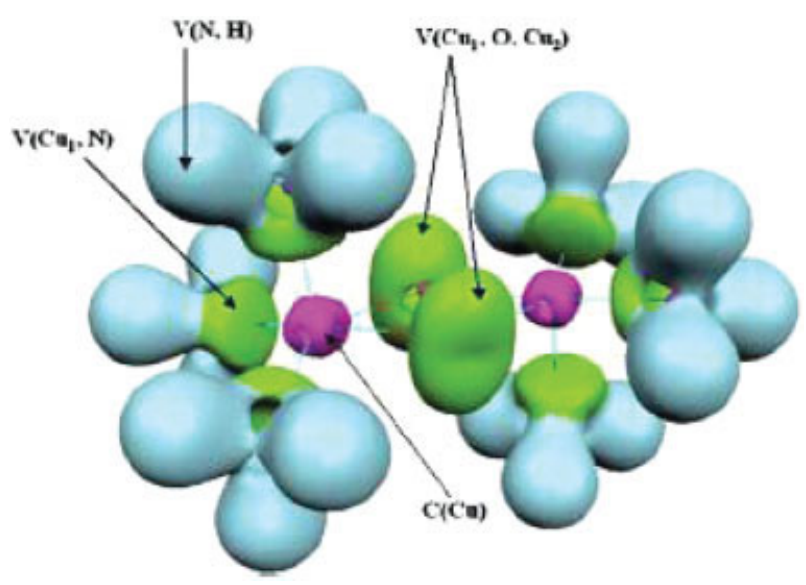

FIGURE 10. Localization domains $(E L F=0.72)$ for a B3LYP/DZVP2 optimized $\mathrm{A}-\mathrm{NH}_{3}$ molecule. Color code: magenta: core, green: valence polysynaptic, light blue: protonated valence disynaptic. Reproduced by permission of Elsevier. [Color figure can be viewed in the online issue, which is available at www. interscience. wiley.com.] 


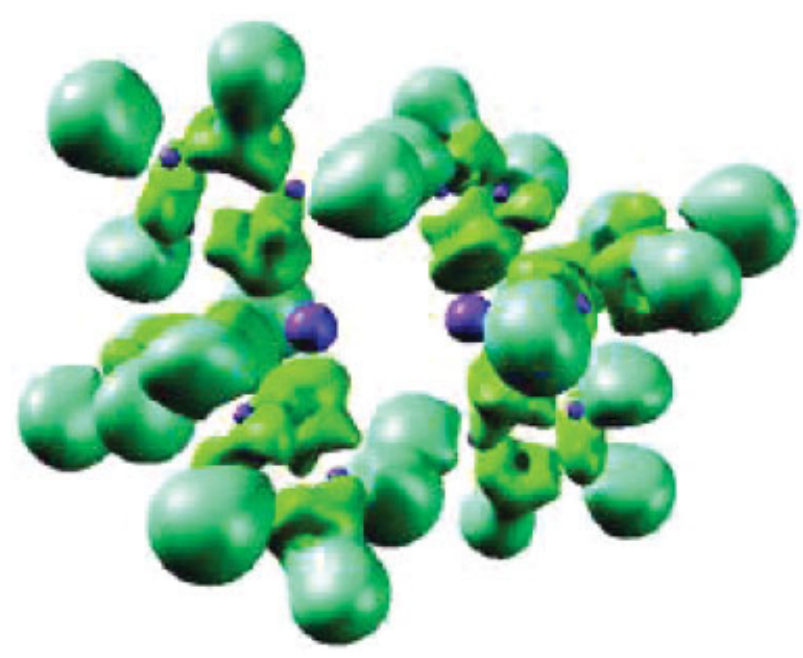

FIGURE 11. ELF localization domains $(\eta=0.7)$ for a B3LYP/LANL2DZ optimized structure of $\mathrm{Cu}_{2}-(\mathrm{ImH})_{6}^{2+}$ model of deoxytyrosinase. Color code: magenta: core; green, valence polysynaptic; light blue: protonated valence disynaptic. Reproduced by permission of The Royal Society of Chemistry on behalf of the Centre National de la Recherche Scientifique. [Color figure can be viewed in the online issue, which is available at www.interscience.wiley. com.]

between $\mathrm{ImH}$ and $\mathrm{O}_{2}$ reduce the charge delocalization on the oxygen observed for the other complexes leading to a better description of the electronic structure compared to $\mathrm{NH}_{3}$. The choice of $\mathrm{ImH}$ as ligand leads to a realistic model, providing a partial antiferromagnetic coupling. The ELF topological analysis was also used to analyze $\mathrm{Cu}-\mathrm{Cu}$ bonding in the case of the deoxygenated tyrosinase [47]. Figure 11 displays the clear absence of such a bond.

\subsection{LEAD TOXICITY}

\subsubsection{Introduction}

In this Part, we would like to emphasize on how the topological analysis of the ELF function, coupled to a visually attractive representation of the basins, can help and provide hints in deciphering some intimate behavior of a non transition cation, namely $\mathrm{Pb}^{2+}$.

A fascinating and intriguing aspect of the coordination chemistry of $\mathrm{Pb}^{2+}$ is its ability to generate either hemidirected or holodirected complexes, which allows introducing the concept of stereochemically active lone pair (see Fig. 12).
In holodirected structures, the ligands adopt a holotropic distribution, whereas in hemidirected structures the ligands appear repelled into a single hemisphere, leaving a void in the complementary hemisphere, which is in fact filled by the valence lone pair associated to the electron belonging to valence shell. The question why, in some cases, this shell remains holotropic whereas in other cases it becomes directional (hemitropic) is not completely understood. More precisely, given a stoichiometric formula, will the corresponding structure be holodirected or hemidirected?

Such a standard question cannot be answered if $\mathrm{Pb}^{2+}$ is involved, as it requires hypothesizing whether the external shell adopts a holotropic shape, or not. In that sense, the VSEPR theory [50, 51] is of a limited use here as illustrated by the two following examples. First, the $\left[\mathrm{Pb}(\mathrm{CO})_{2}\right]^{2+}$ complex (see Fig. 13): if the valence electrons of $\mathrm{Pb}^{2+}$ adopt an holotropic distribution, then the complex will be linear. If not, the complex will be bent in the $C_{2 v}$ symmetry. The second structure is the lowest in energy. If we stay in the $\left[\mathrm{Pb}(\mathrm{CO})_{n}\right]^{2+}$ series, it is easy to understand that for low $n$ values, there will be a competition between holo- and hemidirected structure. For higher $n$ values, it is easy to understand that the steric repulsion between the ligands certainly will favor holodirected species. Intermediate $\mathrm{n}$ values can lead to competitive structures, as shown in Figure 13 for $n=4$ for which a holodirected $T_{\mathrm{d}}$ structure competes with a $\mathrm{C}_{2 \mathrm{v}}$ hemidirected conformation. For $n=6$, a holodirected octahedral species is obtained.

The problem is thus what is the $n$ value corresponding to the topological transition between holo- and hemidirected structures? And, does this transition occur for the same value of $n$ for any $\left[\mathrm{PbL}_{n}\right]^{2+}$ series?

Such questions are not purely academic. An indepth and rationalized theoretical understanding of
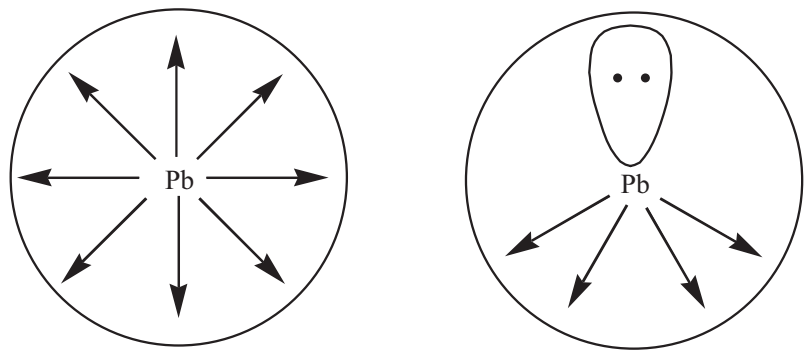

FIGURE 12. $\mathrm{Pb}^{2+}$ complexes can be either holodirected (left) or hemidirected (right) [49]. 


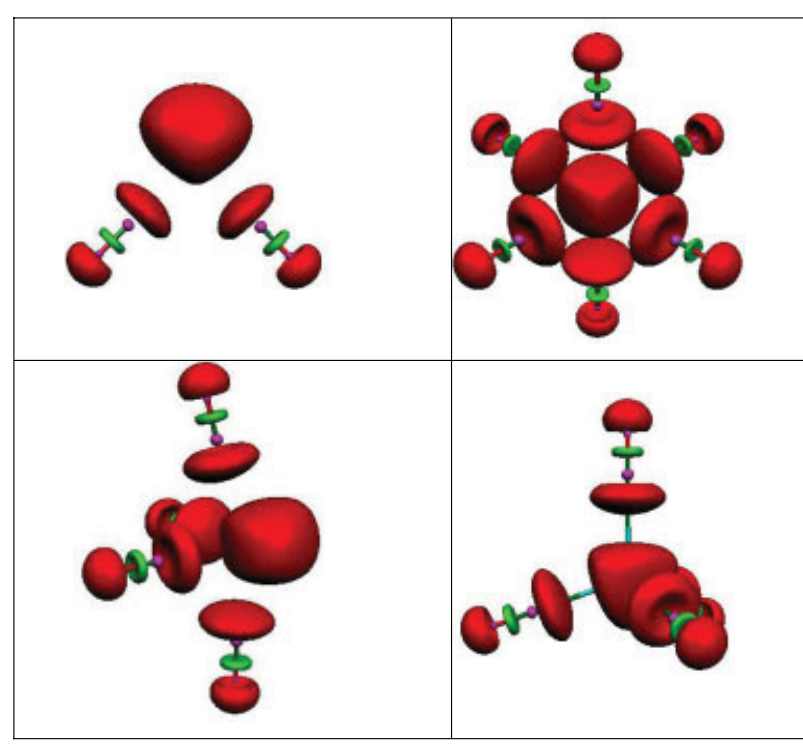

FIGURE 13. Topological analysis of the ELF function $(\eta=0.83)$ for some $\left[\mathrm{Pb}(\mathrm{CO})_{n}\right]^{2+}$ complexes. From top to bottom and from left to right: $(\mathrm{A})\left[\mathrm{Pb}(\mathrm{CO})_{2}\right]^{2+} ;(\mathrm{B})$ $\left[\mathrm{Pb}(\mathrm{CO})_{6}\right]^{2+} ;(\mathrm{C})\left[\mathrm{Pb}(\mathrm{CO})_{4}\right]^{2+}\left(\mathrm{C}_{2 v}\right.$ hemidirected $) ;(\mathrm{D})$ $\left[\mathrm{Pb}(\mathrm{CO})_{4}\right]^{2+}\left(T_{\mathrm{d}}\right.$ holodirected). Core basins $\mathrm{C}(\mathrm{C})$ and $\mathrm{C}(\mathrm{O})$ are in purple, valence disynaptic basins $\mathrm{V}(\mathrm{C}, \mathrm{O})$ in green, and valence monosynaptic basins $\mathrm{V}(\mathrm{O}), \mathrm{V}(\mathrm{C})$, and $\mathrm{V}(\mathrm{Pb})$ in red. [Color figure can be viewed in the online issue, which is available at www.interscience. wiley.com.]

the intimate rules governing the chemistry of $\mathrm{Pb}^{2+}$ would be of course welcomed for the sake of completeness of quantum chemistry in explaining molecular properties. But, ultimately, comes the aim of being able to rationally design specific chelators of the $\mathrm{Pb}^{2+}$ cation usable in vivo, a crucial point in curing saturnism or plumbism.

In the following two sections, we will extract the most significant conclusions of our past or current works on that topic [52-57], and illustrate how ELF has contributed and provided hints relevant to these two lines (the computations reported in this Part has been performed at the B3LYP level of theory using the $6-31+\mathrm{G}^{* *}$ basis sets for all atoms, except for $\mathrm{Pb}^{2+}$ which has been described by the large-core SDD pseudopotential. The visualization of the ELF basins has been obtained with the Molekel package) [58].

\subsubsection{The Hemi/Holo Transition}

The existence of holodirected and hemidirected structures in $\mathrm{Pb}^{2+}$ complexes has been known for long in crystallography. It seems that ShimoniLivny et al. [49] have been among the first ones to initiate a systematic investigation on experimentally known leaded structures, which they coupled to some ab initio computations. Collecting the crystallographic data available for $\mathrm{Pb}$ (II) complexes from the Cambridge Structural Database in its 1996 s version [59], they concluded that "Pb(II) compounds are hemidirected for low coordination numbers (2-5) and holodirected for high coordination numbers (9, 10), but for intermediate coordination numbers (6-8), examples of either type of stereochemistry are found." This is factual, relies on statistics and joins what has been anticipated previously. To go further, they initiated a number of HF (Hartree-Fock) and MP2 computations on a number of systems using the LANL2DZ pseudopotential to describe the metallic cation and the D95 basis set for the other atoms [60]. These calculations were supplemented by NPA and NBO interpretative analyses [61 and references therein]. Despite the intrinsic pioneering quality of this work, the results are unfortunately a bit deceptive as no clear-cut quantitative explanation emerges to discriminate between holo- and hemidirected structures. A strong hybridization of the $6 \mathrm{~s}^{2}$ and $6 \mathrm{p}^{0}$ orbitals can be invoked to explain the strong directionality of the lone pair of $\mathrm{Pb}^{2+}$ in hemidirected structures, but the NBO description of the natural orbital associated to the chemical lone pair reveals in most cases a rather weak weight of the $6 \mathrm{p}$ orbitals, usually less than $10 \%$ (and null for holodirected structures), thus ruling out the hybridization hypothesis. Even the most recent MO diagrams fail to provide any molecular orbital representation of a directed lone pair... whereas the considered structures are clearly hemidirected [62]. The NPA analyses (and the natural electron configurations) appear more appealing and reveal a strong population in the $6 \mathrm{p}$ orbitals in hemidirected complexes. The trouble is that high populations are found also in some low-coordinated holodirected complexes, which illustrates that for such complexes the three components of the $6 \mathrm{p}$ shell are equally occupied in the NPA analyses. It follows that other electronic indicators must be considered to discriminate between both families of structures.

Searching for such an indicator, we have recently considered and systematically investigated the $[\mathrm{Pb}-$ $\left.(\mathrm{CO})_{n}\right]^{2+}(n=0-10)$ model series $[52,57]$. As the topological analysis of the ELF function is able to define a monosynaptic $\mathrm{V}(\mathrm{Pb})$ basin, which accounts altogether for the $6 \mathrm{~s}$ and $6 \mathrm{p}$ orbital populations, and to provide the electronic population and the vol- 
ume of such a basin, we have defined the electronic density of a $\mathrm{V}(\mathrm{Pb})$ basin by:

$$
<\rho>\mathrm{V}_{n}(\mathrm{~Pb})=\mathrm{N}_{n}(\mathrm{~Pb}) / \omega_{n}(\mathrm{~Pb})
$$

where $\mathrm{V}_{n}(\mathrm{~Pb})$ is the monosynaptic $\mathrm{V}(\mathrm{Pb})$ basin for a given $\left[\mathrm{Pb}(\mathrm{CO})_{n}\right]^{2+}$ complex, and $\mathrm{N}_{n}(\mathrm{~Pb})$ and $\omega_{n}(\mathrm{~Pb})$ are, respectively, the population and the volume of this basin. Such calculations have been performed at the B3LYP level, using SDD pseudopotentials for $\mathrm{Pb}^{2+}$, a procedure validated previously $[52,54,58$, 63].

The interesting result $[52,57]$ is that $\langle\rho\rangle_{\mathrm{V}_{n}(\mathrm{~Pb})}$ increases rather linearly up to $n=6$ and becomes constant afterward, reaching a limit of about 15.0 $\times 10^{-3} \mathrm{e}^{-} / \mathrm{ua}^{3}$. For $n<6$, all structures follow the VSEPR rules and can be described as $\mathrm{AX}_{n} \mathrm{E}$ entities. These complexes are hemidirected and the associated $\mathrm{V}_{n}(\mathrm{~Pb})$ basins exhibit a clear distortion: they point outside the complexes and occupy void sites. The transition toward a holodirected structure occurs at $n=6$ (see Fig. 13). From this value, the complexes have to be described as $\mathrm{AX}_{n}$ entities as the valence lone pair has become stereochemically inert and has merged the VSEPR core. The associated ELF $\mathrm{V}_{n}(\mathrm{~Pb})$ basins then exhibit not spherical, but holotropic shapes.

In other words, from $n=0,\langle\rho\rangle_{\mathrm{V}_{n}(\mathrm{~Pb})}$ increases regularly with $n$ : the $\omega_{n}(\mathrm{~Pb})$ volumes decrease and appear being more and more compressed by the ligands. $\langle\rho\rangle_{\mathrm{V}_{n}(\mathrm{~Pb})}$ then reaches a limiting plateau starting at $n=6$ from which $\omega_{n}(\mathrm{~Pb})$ cannot be compressed farther, making $\mathrm{V}_{n}(\mathrm{~Pb})$ loose any role in determining the allowed coordination numbers which become essentially governed by ligand-ligand repulsions.

The question then remains whether a limiting value for $\langle\rho\rangle_{\mathrm{V}_{n}(\mathrm{~Pb})}$ is accidental (namely ligand dependant) or intrinsic. Our preliminary calculations on series of $\left[\mathrm{PbL}_{n}\right]^{2+}$ structures not only reveal that this limit exist for the various ligands considered, but that it is almost constant, within about roughly $10 \%$. For the neutral ligands investigated, the transition occurs at $n=6$. For the more donating anionic ligands, no transition is observed and even for such low values as $n=3$ or 4 (all hemidirected structures), the limiting plateau has already been reached: any supplementary ligand will decoordinate a preexisting ligand or coordinate in the second shell. It also appears that if density $\langle\rho\rangle_{\mathrm{V}_{n}(\mathrm{~Pb})}$ exceeds the limiting value for some geometrical arrangements, the structures will in fact evolve, one way or another, even by expelling ligands in the second coordination sphere and/or switching from holodirected to hemidirected structures, to reach the minimal energy geometry (Van Severen et al., submitted).

To the best of our knowledge, the ELFic $\langle\rho\rangle_{\mathrm{V}_{n}(\mathrm{~Pb})}$ quantity is the sole electronic indicator of whether a given $\mathrm{Pb}^{2+}$ structure will evolve, or stay, into a holo- or hemidirected structure. It is among the rare a priori indicators provided by ELF, an approach usually considered as an a posteriori analyzing tool.

\subsubsection{Models of In Vivo $\mathrm{Pb}^{2+}$ : The Molecular Origin of Saturnism}

Poisoning by heavy metals could be considered as unusual, accidental, and especially rare. That is maybe true, nowadays, for cadmium or mercury, for example. But not for lead, which has become the pollutant the most widely scattered by the sole hand of men [64-66]. By means of deposits in Greenland's ices, its traceability has been established since at least 5,000 years and allows a clearcut knowledge of lead handling by mankind since protohistoric epochs [67-69 and references therein]. Used as a pure metal since the discovering of $\mathrm{cu}^{-}$ pellation, or as alloys, since Antiquity, lead achieved its societal climbing in various molecular or ionic species, in paints, electronics, and adjuvant to oil. All these applications are now banned, which results in new pollution due to its recycling. Despite the progressive interdiction of lead in more and more industrial sectors, production of lead is still increasing and amounted to 7 billion tons in 2006. In facts, the annual production of lead will not decrease before an economically viable solution to replace lead batteries will be found.

The severe medical consequences of lead poisoning, especially for the fetus during pregnancy, or for children will not be detailed here as they can be found in many textbooks or reviews [70-72]. Among other actions, it is now agreed that $\mathrm{Pb}^{2+}$ targets a number of metalloenzymes, displacing the native metallic cations, and thus disturbing, even inhibiting, the expected behavior of these enzymes. The two cases of ALAD ( $\delta$-AminoLevulinic Acid Dehydratase, also called PBGS: PorphoBilinoGen Synthase) which is involved in the first steps of the biochemical synthesis of heme, and calmodulin $(\mathrm{CaM})$ which is involved in the cellular calcium homeostasis, are particularly well documented, and it is now well established that they are especially 


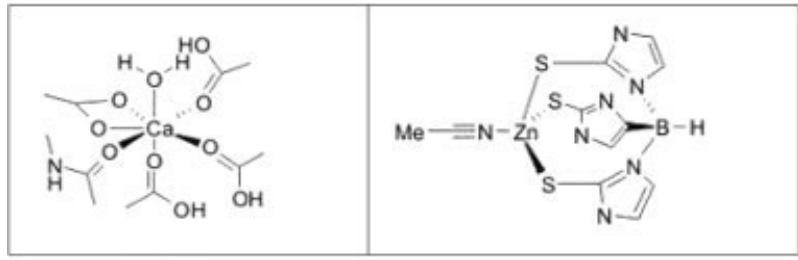

FIGURE 14. Bioinspired models retained for calmodulin (left) and ALAD (right).

attractive to $\mathrm{Pb}^{2+}[73-76]$. In the monomeric ALAD, two metallic sites are structuring: the two $\mathrm{Zn}^{2+}$ cations allow two molecules of $\delta$-aminolevulinic acid to coordinate in a manner that favors condensation into a porphobilinogen molecule. In calmodulin, which is dedicated to the transport and release of $\mathrm{Ca}^{2+}$, four sites are optimized to coordinate four $\mathrm{Ca}^{2+}$ cations. When interacting with other proteins, $\mathrm{Ca}^{2+}$-calmodulin can experiment strong conformational changes that will induce $\mathrm{Ca}^{2+}$ release.

To investigate what happens when $\mathrm{Pb}^{2+}$ displaces the native cation, we have modeled these two enzymatic sites (see Fig. 14), restraining ourselves to the first sphere coordination ligands for CaM [77] and considering a bioinspired model of ALAD designed by Parkin and coll [78]. For ALAD, the native substrate has been modeled by acetonitrile (Fig. 14, right).

Once optimized the native modeled structures and their $\mathrm{Pb}^{2+}$ counterparts, a topological analysis of the ELF function has been performed, the pictorial description of which are reported on Figure 15 $[55,56]$. The most catching result is obtained for ALAD. The native $\mathrm{Zn}^{2+}$ site, initially holodirected, become hemidirected upon the substitution by $\mathrm{Pb}^{2+}$ : the less coordinating ligand, here, the substrate, has been expelled from the first coordination sphere in order for $\mathrm{Pb}^{2+}$ to expand its valence lone pair, here appearing as an electronic shield repelling the nitrogen lone pair of acetonitrile, the model of the natural substrate, and inhibiting its docking. Consequently, ALAD is inhibited in the presence of $\mathrm{Pb}^{2+}$, as observed experimentally.

Things are a priori less clear-cut for what concerns the $\mathrm{Pb}^{2+}$ substitution in CaM. In the native structure, $\mathrm{Ca}^{2+}$ is coordinated in a clearly holodirected environment (Fig. 15, top left). What ELF visually reveals is an attempting emergence of the $\mathrm{V}(\mathrm{Pb})$ basin to evolve into an hemidirected structure. For that purpose, as seen from the careful inspection of the $\mathrm{Pb}^{2+}$-coordinating atom bond lengths, the active site in fact dramatically reorga- nizes to free space to that lone pair $[55,56]$. In that case, it can be anticipated that the protein will not be completely inhibited even if the $\mathrm{Pb}^{2+}$ substitution could complicate the conformational rearrangements that allow freeing $\mathrm{Ca}^{2+}$ from the three remaining sites of CaM. That is what is experimentally observed: no full inhibition, but a decrease of activity.

These results are intrinsically of interest and are confirmed by the studies performed on other $\mathrm{Zn}^{2+}$ or $\mathrm{Ca}^{2+}$ proteic sites [52]: the same behaviors are observed. But it is possible to go beyond these $a$ posteriori interpretations and to test the previously suggested hypothesis that the $\langle\rho\rangle_{\mathrm{V}(\mathrm{Pb})}$ value can be considered as a valuable indicator governing $\mathrm{Pb}^{2+}$ chemistry. That test relies on two ELFic calculations of $\langle\rho\rangle_{\mathrm{V}(\mathrm{Pb})}$ for each model (Table III): (a) its determination from a single point computation on the optimized $\mathrm{Zn}^{2+}$-ALAD or $\mathrm{Ca}^{2+}-\mathrm{CaM}$ structures in which the native cation has been replaced by $\mathrm{Pb}^{2+}$; (b) the fully optimized $\mathrm{Pb}^{2+}$-ALAD or $\mathrm{Pb}^{2+}-$ CaM structures. As seen from Table III, the geometrical relaxation of the structure induces a clear-cut increase of the $\mathrm{V}(\mathrm{Pb})$ volume, indicating that both models reorganize to allow, at its best feasibility, the expansion of the valence lone pair of $\mathrm{Pb}^{2+}$.
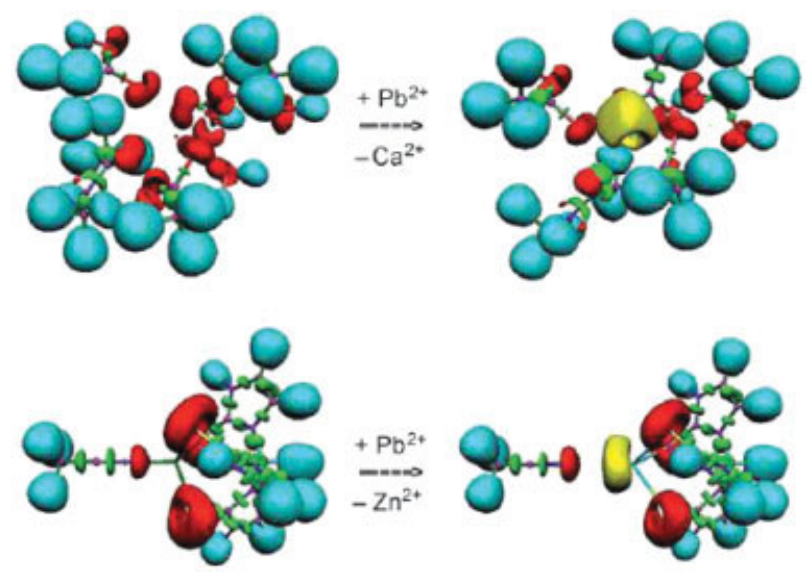

FIGURE 15. ELF localization domains $(\eta=0.85)$ [52, $55,56]$. The $V(X, H)$ basins are shown in turquoise, the lone pair basins in red, the core basins in magenta, and the disynaptic valence basins in green. The valence shell of $\mathrm{Pb}^{2+}$ is represented by the large shaded yellow $\mathrm{V}(\mathrm{Pb})$ basin. Top: bioinspired calmodulin model for the

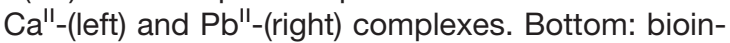
spired ALAD model for the $\mathrm{Zn}^{\prime \prime}$ (left) and $\mathrm{Pb}^{\text {"l-(right) }}$ complexes. [Color figure can be viewed in the online issue, which is available at www.interscience. wiley.com.] 
TABLE III

Variations of the volume, population, and basin density of $\mathrm{V}(\mathrm{Pb})$ in $\mathrm{ALAD}$ and CaM, before and after structural relaxation.

\begin{tabular}{|c|c|c|c|}
\hline & $\begin{array}{l}\text { Volume } \\
\qquad\left(\mathrm{ua}^{3}\right)\end{array}$ & $\begin{array}{c}\mathrm{N}(\mathrm{Pb}) \\
\text { (electrons) }\end{array}$ & $\begin{array}{c}<\rho>_{\mathrm{V}(\mathrm{Pb})} \\
\left(10^{-3} \cdot \mathrm{e}^{-} / \mathrm{ua}^{3}\right)\end{array}$ \\
\hline \multicolumn{4}{|c|}{ ALAD } \\
\hline ALAD geometry & 136 & 2.7 & 19.9 \\
\hline Relaxed & 232 & 2.9 & 12.3 \\
\hline \multicolumn{4}{|c|}{ CaM } \\
\hline CaM geometry & 116 & 2.4 & $20.6 R$ \\
\hline Relaxed & 159 & 2.4 & 15.2 \\
\hline
\end{tabular}

This is in line with the previous discussion. More interesting is the consideration of the $\langle\rho\rangle_{\mathrm{V}(\mathrm{Pb})}$ values. Upon relaxation after $\mathrm{Pb}^{2+}$ substitution, it decreases from 19.9 to 12.3 for ALAD and from 20.6 to $15.2 \times 10^{-3} \mathrm{e}^{-} / \mathrm{ua}^{3}$ for CaM. Such a decrease is not anecdotal if we refer to the previously reported value of $15.0 \times 10^{-3} \mathrm{e}^{-} / \mathrm{ua}^{3} \pm 10 \%$ deduced from the $\left[\mathrm{PbL}_{n}\right]^{2+}$ series, which seems to be the limiting value that can be reached for $\langle\rho\rangle_{\mathrm{V}(\mathrm{Pb})}$ basins. In the ALAD model, this quantity amounts to $19.9 \times$ $10^{-3} \mathrm{e}^{-} / \mathrm{ua}^{3}$ when simply substituting native $\mathrm{Zn}^{2+}$ by $\mathrm{Pb}^{2+}$ : it is over that limiting value. The same situation holds for nonreoptimized $\mathrm{Pb}^{2+}-\mathrm{CaM}$. After full reoptimization of these initially holodirected structures, rather hemidirected structures are obtained, and the $\langle\rho\rangle_{\mathrm{V}(\mathrm{Pb})}$ values have decreased to 12.3 and $15.2 \times 10^{-3} \mathrm{e}^{-} / \mathrm{ua}^{3}$, below what we have called the "limiting" value. Such behavior has been observed for other model systems of proteic sites [52].

From that viewpoint, the topological analysis of the ELF function again appears as a tool able to go beyond a posteriori interpretations or descriptions. We here show that it can be used to anticipate not necessarily what exactly will happen, but at least that something will happen to a molecular structure if it does not fulfill some electronic constraints. Further work on that line is in progress.

\subsubsection{Dynamical Aspects}

The previously reported studies clearly highlight that the analysis of the ELF function can provide in-depth insights on the coordination chemistry of $\mathrm{Pb}^{2+}$. Of course, the visualization of the external lone pair of the cation is appealing, but, beyond, the analysis of the volumes and populations of the
$\mathrm{V}(\mathrm{Pb})$ basin allows to get a quantitative description of the holodirected and hemidirected structures, which can help in predicting if a given structure is stable or if it will evolve to reach an holodirected or hemidirected geometry that fulfils some restrictions

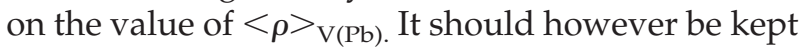
in mind that for intermediate coordination numbers, a competition can occur between the two families of complexes. Clearly, in the gas phase cluster approach considered up to now, it seems that hemidirected complexes are favored, but that trend could be reversed if considering either the full environment or dynamic aspects. Such a flexibility of the lone pair has been pointed out in the dynamic treatment of solvated $\mathrm{Pb}^{2+}[52,54]$ : from a 12-ps simulation performed within the Car-Parrinello scheme, the hydrated $\mathrm{Pb}^{2+}$ ion is found to be heptacoordinated in a dynamically holodirected, but statically hemidirected arrangement corresponding roughly to a distorted pentagonal bipyramid. It follows that considering the dynamical aspects for this fluxional character of the lone pair may be essential to recover some properties of lead(II) complexes.

\section{Conclusions}

In this paper, we highlight the large variety of information that can be gained from the application of the ELF related analysis tools to a wide range of systems of biological interest. In that connection, a function can be used to quantitatively characterize interaction as diverse as H-bonds, partially double $\mathrm{C}-\mathrm{N}$ bonds, metal-ligand bonds, and even nonbonding lone pairs. The possibility to rely on unified concepts to examine systems as complex in term of bonding interaction as biological systems is a great opportunity to unify and compare the competitive interaction responsible for both their structure and reactivity. Nevertheless, the way to this point is long, as highlighted by the path already realized in the field of chemical applications.

The first review article on ELF published 10 years ago by Savin et al. [79] mostly reports applications on inorganic systems carried out in only qualitative and graphical ways: it aimed at understanding the bonding between metals and particularly in intermetallic phases. For these systems, ELF has been found to be an unsurpassed tool of analysis of the electron density since it enabled not only to find the localization regions of electrons but also to localize missing atoms in 
incompletely determined structures. A step ahead has been made with the gradient dynamical system approach [12] which enables the partition of the density into basin of attractors closely related with Gillespie's electronic domains, and therefore with the Lewis model [80]. The availability of a robust mathematical model of the bonding led to the introduction of new concepts and of a new vocabulary [81]. The calculation of the basin populations provided a very chemical population analysis, which, completed by the related covariance matrix [14], reactualized Ingold's concept of mesomery [82]. Although ELF had been used to describe and explain the bonding in molecules and solids, it appeared that "elfology" could be also predictive. For example, it was shown that the protonation sites in bases can be predicted from ELF derived topological considerations [83] and that the value of the function at some index 1 critical points provided reactivity indexes for the regioselectivity of the aromatic electrophilic substitution [84]. Thanks to these efficient tools, the ELF analysis was applied in a systematic way to the different types of bonding [85] belonging to both organic and inorganic chemistry as well as to structural concepts [86] or effects [87]. The present review shows that all the experience gained along of the last fifteen years can be transferred to the complex field of the modeling of biological relevant systems.

Another important issue of the ELF analysis is the study of chemical reaction mechanisms for which the catastrophe theory provides an elegant theoretical framework [88] and which has been applied to proton transfer reactions [89] and in a rather systematic way to cyclization reactions [90] and two-state reactions [91]. The investigation of reaction mechanisms remains expensive in terms of CPU, nevertheless, we hope to be able to carry out such calculations and analysis on important biochemical reactions, for example on systems interesting the enzyme catalysis such as the rubisco (D-ribulose-1,5-biphosphate carboxylase/ oxygenase) for which ELF has already been used to discuss the structure of the transition states [92].

\section{ACKNOWLEDGMENTS}

The calculations have been performed at IDRIS (F. 91403, Orsay, France) and CINES (F. 34000 Montpellier, France) national supercomputing cen- ters as well as at the CCRE of the Université Pierre et Marie Curie (F. 75252, Paris, France) and at the CRIHAN (F. 76800 Saint-Etienne-du-Rouvray, France) regional supercomputing center.

\section{References}

1. Coulson, C. A. Valence; Clarendon: Oxford, 1952.

2. Becke, A. D.; Edgecombe, K. E. J Chem Phys 1990, 92, 5397.

3. Gillespie, R. J.; Robinson, E. A. J Comput Chem 2007, 34, 396.

4. Lewis, G. N. J Am Chem Soc 1916, 38, 762.

5. Lewis, G. N. Valence and the Structure of Atoms and Molecules; Dover: New York, 1966.

6. Abraham, R. H.; Shaw, C. D. Dynamics: The Geometry of Behavior; Addison: Wesley, 1992.

7. Abraham, R. H.; Marsden, J. E. Foundations of Mechanics; Addison: Wesley, 1994.

8. Bader, R. F. W. Atoms in Molecules: A Quantum Theory; Oxford University Press: Oxford, 1990.

9. Dobson, J. F. J Chem Phys 1991, 94, 4328.

10. Savin, A.; Jepsen, O.; Flad, J.; Andersen, O. K.; Preuss, H.; von Schnering, H. G. Angew Chem Int Ed Engl 1992, 31, 187.

11. Silvi, B. J Phys Chem A 2003, 107, 3081.

12. Silvi, B.; Savin, A. Nature 1994, 371, 683.

13. Häussermann, U.; Wengert, S.; Nesper, R. Angew Chem Int Ed Engl 2069, 1994, 33.

14. Silvi, B. Phys Chem Chem Phys 2004, 6, 256.

15. Mezey, P. G. Can J Chem 1993, 72, 928.

16. Pilmé, J.; Piquemal, J.-P. J Comput Chem 2008, online (DOI: 10.1002/jcc. 20904).

17. Popelier, P. L. A. Atoms in Molecules: An Introduction; Prentice-Hall: Harlow, UK, 2000.

18. Frisch, M. J.; Trucks, G. W.; Schlegel, H. B.; Scuseria, G. E.; Robb, M. A.; Cheeseman, J. R.; Zakrzewski, V. G.; Montgomery, A. J., Jr.; Stratmann, R. E.; Burant, J. C.; Dapprich, S.; Millam, J. M.; Daniels, A. D.; Kudin, K. N.; Strain, M. C.; Farkas, O.; Tomasi, J.; Barone, V.; Cossi, M.; Cammi, R.; Mennucci, B.; Pomelli, C.; Adamo, C.; Clifford, S.; Ochterski, J.; Petersson, G. A.; Ayala, P. Y.; Cui, Q.; Morokuma, K.; Malick, D. K.; Rabuck, A. D.; Raghavachari, K.; Foresman, J. B.; Cioslowski, J.; Ortiz, J. V.; Baboul, A. G.; Stefanov, B. B.; Liu, G.; Liashenko, A.; Piskorz, P.; Komaromi, I.; Gomperts, R.; Martin, R. L.; Fox, D. J.; Keith, T.; Al-Laham, M. A.; Peng, C. Y.; Nanayakkara, A.; Challacombe, M.; Gill, P. M. W.; Johnson, B.; Chen, W.; Wong, M. W.; Andres, J. L.; Gonzalez, C.; Head-Gordon, M.; Replogle, E. S.; Pople, J. A. Gaussian 98, Revision A. 9; Gaussian Inc.: Pittsburgh PA, 1998.

19. Becke, A. D. Phys Rev A 1988, 38, 3098.

20. Becke, A. D. J Chem Phys 1993, 98, 5648.

21. Perdew, J. P.; Burke, K.; Ernzerhof, M. Phys Rev Lett 1996, 77, 3865.

22. Silvi, B.; Wieczorek, R.; Latajka, Z.; Alikhani, M. E.; Dkhissi, A.; Bouteiller, Y. J Chem Phys 1999, 111, 6671.

23. Noury, S.; Krokidis, X.; Fuster, F.; Silvi, B. TopMoD package; Laboratoire de Chimie Théorique, UPMC Paris, France, 1997. 
24. Noury, S.; Krokidis, X.; Fuster, F.; Silvi, B. Comput Chem 1999, 23, 597.

25. Amira 3.0. TGS, Template Graphics Sofware, Inc.: San Diego, USA, 2002.

26. Flükiger, P.; Lüthi, H.-P.; Portmann, S.; Weber, J. Molekel 4.0. Swiss National Supercomputing Centre CSCS: Manno (Switzerland), 2000.

27. (a) Piquemal, J.-P.; Cisneros, G. A.; Gresh, N.; Reinhardt, P.; Darden, T. A. J Chem Phys 2006, 124, 104101; (b) Piquemal, J.-P.; Perera, L.; Cisneros, G. A.; Ren, P.; Pedersen, L. G.; Darden, T. A. J Chem Phys 2006, 125, 054511. (c) Piquemal, J.-P.; William-Hubbard, B.; Fey, N.; Deeth, R. J.; Gresh, N.; Giessner-Prettre, C. J Comput Chem 2003, 24, 1963.

28. Gresh, N.; Cisneros, G. A.; Darden, T. A.; Piquemal, J.-P. J Chem Theory Comput 2007, 3, 1960.

29. Mantz, Y. A.; Gérard, H.; Iftimie, R.; Martyna, G. J. J Am Chem Soc 2004, 126, 4080.

30. Mantz, Y. A.; Gérard, H.; Iftimie, R.; Martyna, G. J. J Phys Chem B 2006, 110, 13523.

31. (a) Wiberg, K. B.; Laidig, K. E. J Am Chem Soc 1987, 109, 5935; (b) Fogarasi, G.; Szalay, P. G. J Phys Chem A 1997, 101, 1400; (c) Lauvergnat, D.; Hiberty, P. C. J Am Chem Soc 1997, 119, 9478; (d) Basch, H.; Hoz, S. Chem Phys Lett 1998, 294, 117; (e) Quiñonero, D.; Frontera, A.; Capó, M.; Ballister, P.; Suñer, G. A.; Garau, C.; Deyá, P. M. New J Chem 2001, 25, 259; (f) Mo, Y.; Schleyer, P. v. R.; Wu, W.; Lin, M.; Zhang, Q.; Gao, J. J Phys Chem A 2003, 107, 10011.

32. Chataigner, I.; Panel, C.; Gérard, H.; Piettre, S. R. Chem Commun 2007, 3288.

33. (a) Kermack, W. O.; Robinson, R. J. J Chem Soc, 1922, 121, 427; (b) Griffith, R.; Bremmer, J. B.; Titmuss, S. J Comput Chem 1997, 18, 1211.

34. Gautier, A.; Pitrat, D.; Hasserodt, J. Bioorg Med Chem 2006, $14,3835$.

35. (a) Bürgi, H. B.; Dunitz, J. D. Acc Chem Res 1983, 16, 153; (b) Studer, M.; Blaser, H.-U.; Exner, C. Adv Synth Catal 2003, 1/2, 45; (c) Griffith, R.; Bremmer, J. B. J Comput-Aided Mol Des 1999, 13, 69; (d) Leonard, N. J. Rech Chem Prog 1956, 17, 243; (e) Leonard, N. J Chem Res 1979, 12, 423.

36. Pilmé, J.; Berthoumieux, H.; Fleurat-Lessard, P.; Robert, V. Chem Eur 2007, 13, 5388.

37. Pauling, L. J Am Chem Soc 1931, 53, 3225.

38. Fourré, I.; Silvi, B. Heteroat Chem 2007, 18, 135.

39. Fourré, I.; Bergès, J. J Phys Chem A 2004, 108, 898.

40. Alikhani, M. E.; Fuster, F.; Silvi, B. Struct Chem 2005, 16, 203.

41. Fuster, F.; Silvi, B. Theor Chem Acc 2000, 104, 13.

42. Fuster, F.; Silvi, B.; Berski, S.; Latajka, Z. J Mol Struct 2000, 555,75 .

43. Gutierrez-Oliva, S.; Joubert, L.; Adamo, C.; Bulat, F.; Zagal, J.; Toro-Labbe, A. J Phys Chem A 2006, 110, 5102.

44. Guerra, C. F.; Bickelhaupt, F. M.; Snijders, J. G.; Baerends, E. J. Chem Eur J 1999, 5, 3581.

45. Fonseca-Guerra, C.; Bickelhaupt, F.; Snijders, J.; Baerends, E. J Am Chem Soc 2000, 122, 4117.

46. (a) Ross, P. K.; Solomon, E. I. J Am Chem Soc 1991, 113, 3246; (b) Chen, P.; Solomon, E. I. J Inorg Biochem 2002, 88, 368; (c) Cramer, C. J.; Smith, B. A.; Tolman, W. B. J Am Chem Soc 1996, 118, 11283; (d) Flock, M.; Pierloot, K. J Phys Chem A 1999, 103, 95; (e) Lind, T.; Siegbahn, P. E. M.; Crabtree, R. H.
J Phys Chem B 1999, 103, 1193; (f) Siegbahn, P. E. M. Faraday Discussions 2003, 124, 289; (g) Murthy, N.; Mahroof-Tahir, M.; Karlin, K. D. Inorg Chem 2001, 40, 628; (h) Santagostini, L.; Gullotti, M.; Monzani, E.; Casella, L.; Dillinger, R.; Tuczek, F. Chem Eur J 2000, 6, 519; (i). Rode, M. F.; Werner, H. J. Theor Chem Acc 2005, 4/5, 247; (j) Cramer, C. J.; Wloch, M.; Piecuch, P.; Puzzarini, C., Gagliardi, L. J Phys Chem A, 2006, $110,5$.

47. Piquemal, J.-P.; Maddaluno, J.; Silvi, B.; Giessner-Prettre, C. New J Chem 2003, 27, 909.

48. Piquemal, J.-P.; Pilmé, J. J Mol Struct (THEOCHEM) 2006, 764, 77.

49. Shimoni-Livny, L.; Glusker, J. P.; Bock, C. W. Inorg Chem 1998, 37, 1853.

50. Gillespie, R. G.; Hargittai, I. The VSEPR Model of Molecular Geometry; Allyn and Bacon: Boston, MA, 1991.

51. Gillespie, R. J.; Popelier, P. L. A. Chemical Bonding and Molecular Geometry; Oxford University Press: Oxford, UK, 2001.

52. Gourlaouen, C. PhD Thesis of the University Paris 6; Caractérisation théorique de I'influence de la substitution de cations natifs par le plomb dans des composés d'interêt biologique; University Paris: Paris, France, defended September 2006.

53. Gourlaouen, C.; Piquemal, J.-P.; Parisel, O. J Chem Phys 2006, 124, 174311.

54. Gourlaouen, C.; Gérard, H.; Parisel, O. Chem Eur J 2006, 12, 5024.

55. Gourlaouen, C.; Parisel, O. Angew Chem Int Ed Engl 2007, $46,553$.

56. Gourlaouen, C.; Parisel, O. Angew Chem 2007, 119, 559.

57. Gourlaouen, C.; Gérard, H.; Piquemal, J.-P.; Parisel, O. Chem Eur J 2008, 14, 2730.

58. Kuelche, W.; Dolg, M.; Stoll, H.; Preuss, H. Mol Phys 1991, $74,1245$.

59. Allen, F. H.; Bellard, S.; Brice, M. D.; Cartwright, B. A.; Doubleday, A.; Higgs, H.; Hummelink, T.; Hummelink-Peters, B. G.; Kennard, O.; Motherwell, W. D. S.; Rodgers, J. R.; Watson, D. G. Acta Crystallogr B 1979, 35, 2331.

60. (a) Hay, P. J.; Wadt, W. R. J Chem Phys 1985, 82, 270; (b) Wadt, W. R.; Hay, P. J. J Chem Phys 1985, 82, 284; (c) Hay, P. J.; Wadt, W. R. J Chem Phys 1985, 82, 299.

61. (a) Reed, A. E.; Curtis, L. A.; Weinhold, F. Chem Rev 1988, 88, 899; (b) Glendening, E. D.; Reed, A. E.; Carpenter, J. E.; Weinhold, F. NBO version 3.1; Theoretical Chemistry Institute; University of Wisconsin; Madison, 1988.

62. Jarzecki, A. A. Inorg Chem 2007, 46, 7509.

63. Gourlaouen, C.; Piquemal, J.-P.; Saue, T.; Parisel, O. J Comput Chem 2006, 27, 142.

64. Patterson, C. C. Arch Environ Health 1965, 11, 344.

65. (a) Needleman, H. L. Environ Res 2000, 84, 20; (b) Needleman, H. L. Environ Res 1998, 78, 79; (c) Needleman, H. L. Environ Res 1997, 74, 95.

66. Hernberg, S. Am J Ind Med 2000, 38, 44.

67. Old Testament: Zc 5:7; Zc 5:8; Nb 31:22; Ezk 27:12.

68. Rosman, K. J. R.; Chisholm, W.; Hong, S.; Candelone, J.-P.; Boutron, C. F. Environ Sci Technol 1997, 31, 3413. 


\section{TOPOLOGICAL ANALYSIS OF THE ELECTRON LOCALIZATION FUNCTION}

69. Renberg, I.; Bindler, R.; Brännvall, M.-L. Holocene 2001, 11, 511.

70. Godwin, H. A. Curr Opin Chem Biol 2001, 5, 223.

71. Cory-Slechta, D. A.; Pound, J. G. In Handbook of Neurotoxicology; Chang, L. W., Dyers, R. S., Eds.; Marcel Dekker: New York, 1995; p 322.

72. Andersen, O. Chem Rev 1999, 99, 2683.

73. Lippard, S. J.; Berg, J. M. Principles of Bioinorganic Chemistry, University Science Books: Sausalito, CA, 1994.

74. Messerschmidt, A.; Huber, R.; Wieghardt, K.; Poulos, T., Eds. Collective, Handbook of Metalloproteins, Vol. III; Wiley: New York, 2004.

75. Reichl, F.-X. Taschenatlas der Toxikologie; George Thieme Verlag: Stuttgart; 2002.

76. Koolman, J.; Röhm, K.-H. Taschenatlas der Biochemie; George Thieme Verlag: Stuttgart, 2003.

77. Chattopadhyaya, R.; Meador, W. E.; Means, A. R.; Quiocho, F. A. J Mol Biol 1992, 228, 1177.

78. Parkin, G. Chem Rev 2004, 104, 699.

79. Savin, A.; Nesper, R.; Wengert, S.; Fässler, T. F. Angew Chem Int Ed Engl 1997, 36, 1809.

80. Silvi, B.; Fourré, I.; Alikhani, E. Monatshefte Chemie 2005, $136,855$.

81. Silvi, B. J Mol Struct 2002, 614, 3.

82. (a) Ingold, C. K. Nature 1934, 133, 946; (b) Ingold, C. K. Nature 1938, 141, 314.

83. Fuster, F.; Silvi, B. Chem Phys 2000, 252, 279.

84. (a) Fuster, F.; Sevin, A.; Silvi, B. J. Phys Chem A 2000, 104, 852; (b)Fuster, F.; Silvi, B.; Berski, S.; Latajka, Z. J Mol Struct 2000, 555, 75.

85. (a) Fuster, F.; Silvi, B. Theor Chem Acc 2000, 104, 13; (b) Silvi, B.; Gatti, C. J Phys Chem A 2000, 104, 947; (c) Choukroun, R.; Donnadieu, B.; Zhao, J. S.; Cassoux, P.; Lepetit, C.; Silvi, B. Organomet 2000, 19, 1901; (d) Llusar, R.; Beltrán, A.; Andrés, J.; Fuster, F.; Silvi, B. J Phys Chem A 2001, 105, 9460; (e)
Noury, S.; Silvi, B.; Gillespie, R. G. Inorg Chem 2002, 41, 2164; (f) Silvi, B.; Pilmé, J.; Fuster, F.; Alikhani, E. M. In Metal-Ligand Interactions in Molecular, Nano, Micro, and Macro-Systems in Complex Environments; Russo, N.; Witko, M., Eds.; NATO-ASI Series; Kluwer: Dordrecht, 2003; (g) Pilmé, J.; Silvi, B.; Alikhani, M. J Phys Chem A 2003, 107, 4506; (h) Chevreau, H.; Martinsky, C.; Sevin, A.; Minot, C.; Silvi, B. New J Chem 2003, 27, 1049; (i) Shaiks, S.; Danovich, D.; Silvi, B.; Lauvergnat, D.; Hiberty, P. Chem Eur J 2005, 21, 6358; (j) Polo, V.; Andrés, J.; Silvi, B. J Comput Chem 2007, $28,857$.

86. (a) Santos, J. C.; Tiznado, W.; Contreras, R.; Fuentealba, P. J. Chem Phys 2004, 120, 1670; (b) Poater, J.; Duran, M.; Solà, M.; Silvi, B. Chem Rev 2005, 105, 3911.

87. Fourré, I.; Gérard, H.; Silvi, B. J Mol Struct (THEOCHEM) 2007, 811, 69.

88. Krokidis, X.; Noury, S.; Silvi, B. J Phys Chem A 1997, 101, 7277.

89. (a) Krokidis, X.; Goncalves, V.; Savin, A.; Silvi, B. J. Phys Chem A 1998, 102, 5065; (b) Krokidis, X.; Vuilleumier, R.; Borgis, D.; Silvi, B. Mol Phys 1999, 96, 265.

90. (a) Berski, S.; Andrés, J.; Silvi, B.; Domingo, L. J. Phys Chem A 2003, 107, 6014; (b) Polo, V.; Andrés, J.; Castillo, R.; Berski, S.; Silvi, B. Chem Eur J 2004, 10, 5165; (c) Polo, V.; Andrés, J. J Comp Chem 2005, 26, 1427; (d) Santos, J. C.; Polo, V.; Andrés, J. Chem Phys Lett 2005, 406, 393; (e) Berski, S.; Andrés, J.; Silvi, B.; Domingo, L. R. J Phys Chem A 2006, 110, 13939; (f) Santos, J. C.; Andrés, J.; Aizman, A.; Fuentealba, P.; Polo, V. J Phys Chem A 2005, 109, 3687.

91. (a) Michelini, M. C.; Sicilia, E.; Russo, N.; Alikhani, M. E.; Silvi, B. J. Phys Chem A 2003, 107, 4862; (b) Michelini, M. C.; Russo, N.; Alikhani, M. E.; Silvi, B. J Comp Chem 2004, 25, 1647; (c) del Carmen Michelini, M.; Russo, N.; Alikhani, M. E.; Silvi, B. J Comput Chem 2005, 26, 1284.

92. Oliva, M.; Safont, V. S.; Andrés, J.; Tapia, O. Chem Phys Lett 2001, 340, 391. 